\title{
Predetermined Refinement: the Earliest Levallois of the Kapthurin Formation
}

\author{
Ceri Shipton $^{1,2}$ (I)
}

Accepted: 15 December 2021

(c) The Author(s) 2022

\begin{abstract}
Levallois technology characterizes the Middle Stone Age/Middle Palaeolithic, but one of its earliest manifestations is from the preceding Acheulean of the Kapthurin Formation, in the Rift Valley of east Africa. Here, $400 \mathrm{ka}$, hominins were creating large flake blank handaxes and cleavers through Levallois knapping. Comparing these tools with other Rift Valley Acheulean assemblages made on large flakes shows those of the Kapthurin Formation are distinguished by their thinness. This was achieved through symmetrical centripetal preparation of gentle upper surface convexities on the Levallois cores, the creation of a protruding facetted platform, and proximal bevelling of the upper surface. A large elongate flake blank was struck from the facetted platform, then finished with marginal trimming to create the symmetrical and regular edge of the handaxe or cleaver. As they were used for the creation of handaxes and cleavers, the Kapthurin Acheulean Levallois cores and flakes are much larger than that of the Middle Stone Age, with overshot flakes from excessive force a more frequent error. The Acheulean Levallois is further distinguished from those of the Middle Stone Age by the lack of recurrent flaking, with cores apparently producing only a single preferential flake without any repreparation of the main flaking surface, despite the cores being big enough for further large blank removals, and even if the preferential removal overshot and was abandoned. The key advantage offered by Levallois in general is large thin elongate flakes. In its Kapthurin Acheulean manifestation, Levallois was used to create an individual tool, but in the Middle Stone Age it was often used to make toolkits.
\end{abstract}

Keywords Acheulean $\cdot$ Handaxe $\cdot$ Cleaver $\cdot$ Large flake blanks $\cdot$ MSA

Ceri Shipton

c.shipton@ucl.ac.uk

1 Institute of Archaeology, University College London, London, UK

2 McDonald Institute for Archaeological Research, University of Cambridge, Cambridge, UK

Published online: 12 February 2022 


\section{Introduction}

Levallois is the most hierarchically complex knapping mode of the Palaeolithic (Muller et al., 2017), and is associated with both Neanderthals (Moncel et al., 2020) and early Homo sapiens (Richter et al., 2017). In its classic definition (Boëda, 1994; Van Peer, 1992) it involves flaking a bifacial disc of stone with the two hemispheres having a hierarchical relationship, such that one is primarily a platform for striking flake products from the other. Critically, the main flaking surface is shaped to predetermine the form of the products, while the main platform has many small flakes removed (facetting) to isolate and strengthen it prior to the forceful Levallois flake removal. Levallois flakes are consequently large relative to the size of the core (preferential), and they are longer than they are wide (elongate).

Levallois is the characteristic technology of the Middle Stone Age (MSA), but it was also used in both the Later Stone Age (LSA) (Pleurdeau et al., 2014; Shipton et al., 2021) and occasionally at Early Stone Age (ESA) Acheulean sites. Seven large Levallois and Levallois-like cores for making Acheulean biface blanks have been reported from Taung in southern Africa, but they are a rare component $(<15 \%)$ of an undated larger assemblage (Kuman, 2001: 11). Some sites in the Horn of Africa have Acheulean handaxes and cleavers in association with Levallois cores, but the latter are generally too small to have been used in creating blanks for the former. These include an undated industry from northern Somaliland (Clark, 1954: 160-169), and the 160 ka Upper Herto Member of Ethiopia's Middle Awash valley, where the lithics were found in association with early Homo sapiens fossils (Sahle et al., 2019). In North Africa, the final Acheulean from the Moroccan site of Sidi-Abderrahman (extension and Cap Chatelier localities) has small Levallois cores (Biberson, 1961: 453-462), which likely date to less than $400 \mathrm{ka}$ (Gallotti et al., 2021; Raynal et al., 2001). At Amane Oukider in Morocco, Acheulean large flake blanks were being produced on Levallois cores, but the assemblage is an undated surface collection (Arzarello et al., 2012).

The earliest date suggested for Levallois anywhere in the world is from the 800-700 ka Acheulean site of Gesher Benot Ya'aqov in the Levant where a single large core and numerous small cores are classified as such (Goren-Inbar et al., 1994, 2018). However, these cores do not display the combination of hierarchically arranged surfaces, with shaping of the upper surface, platform facetting on the lower surface, and preferential flaking at the end of the reduction sequence (Goren-Inbar et al., 2018: 208-213), that would be required to meet strict definitions of Levallois. Perhaps the earliest well-dated and unambiguous instance of Levallois technology is from the Acheulean of the Kapthurin Formation to the southwest of Lake Baringo, Kenya, where it was used to make large flake blanks for handaxes and cleavers 400 ka (Blegen et al., 2018; Gowlett, 1999; Leakey et al., 1969; McBrearty, 1999; Tryon et al., 2005). This paper characterizes the Levallois products from this early occurrence through statistical comparison with flake blank handaxes and cleavers from other east African Acheulean sites. In addition, the Acheulean Levallois cores from the Kapthurin Formation 
are compared through qualitative and quantitative comparisons to Middle Stone Age equivalents both from around Lake Baringo and further afield.

\section{The Kapthurin Formation Acheulean}

The Kapthurin Formation is a series of Middle and Late Pleistocene sedimentary and volcanic deposits exposed to the west of Lake Baringo in the eastern Rift Valley (Fig. 1). Several Acheulean and MSA localities have been discovered in the Formation which is named after the Kapthurin River that incises it. A sequence of tephras have been dated and correlated to provide a robust chronology for the Kapthurin

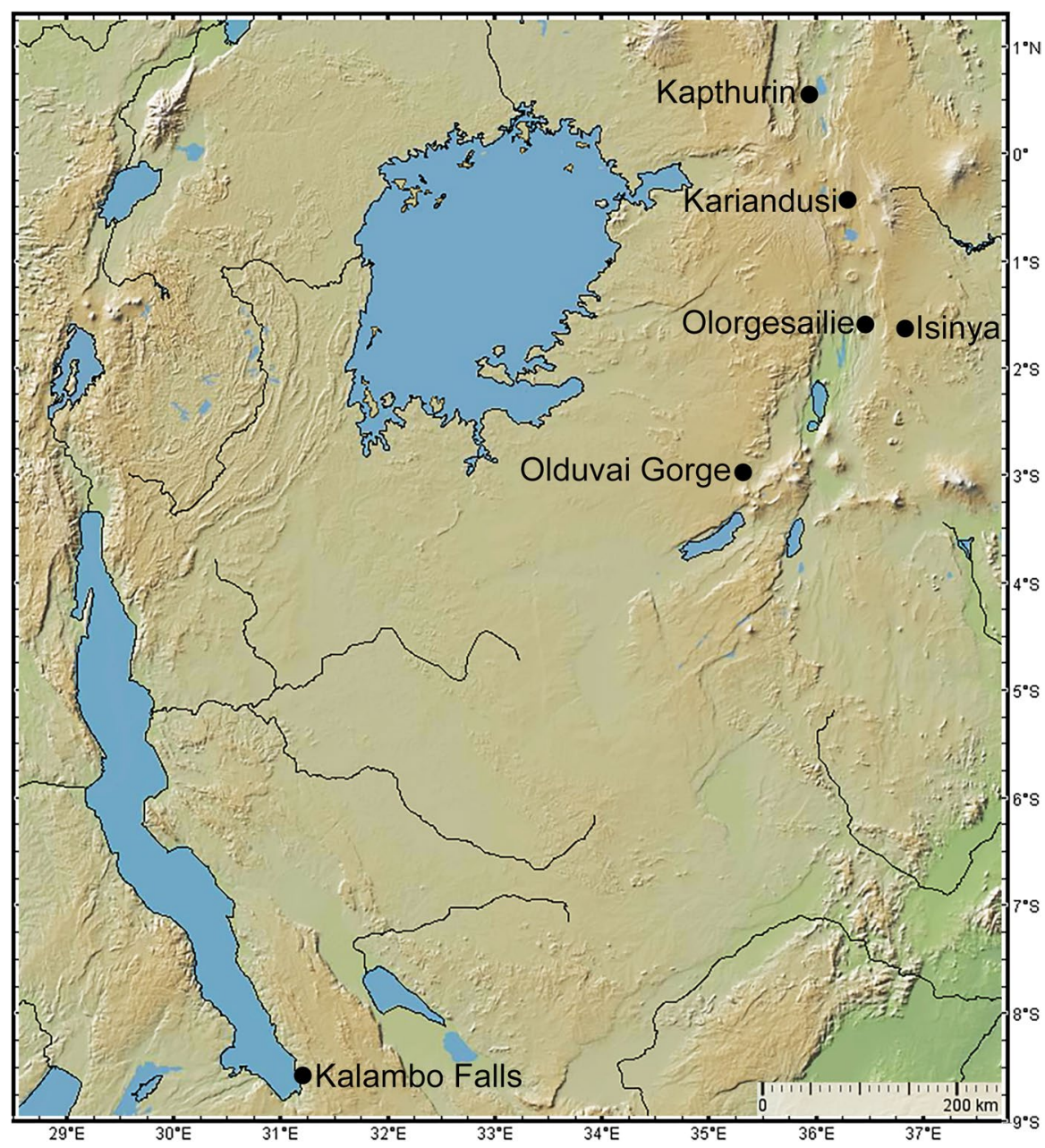

Fig. 1 Location of Olduvai Gorge and the Acheulean assemblages used in this study. Figure made with GeoMapApp (www.geomapapp.org) / CC BY (Ryan et al., 2009) 
sequence (Blegen et al., 2018; Tryon \& McBrearty, 2006). The artefacts used in this study derive from excavations and stratigraphically controlled surface collections conducted by Margaret Leakey and colleagues in 1966 (Leakey et al., 1969), supplemented by later collections of a handaxe and cleaver by Peter Tallon, and a refitting Levallois flake by Sally McBrearty (who used the site code GnJh-03).

Fieldwork was conducted by Leakey and colleagues in two sites $<2 \mathrm{~km}$ apart on either side of the Kapthurin river: the Living Site, comprised of four localities, of which the densest was the Leakey Handaxe Area; and the Factory Site, which included a dense locality called the Paul Abell Site. Systematic surface collections were made at the Living Site, which included 25 handaxes (described as ovates), 17 cleavers (including 'chisel-ended' pieces), and occasional Levallois cores and flakes (Leakey et al., 1969). Two thirds of the handaxes and cleavers were clearly made on flake blanks in which strike direction was apparent from the remnant ventral surface. In the remaining third it was not possible to tell strike direction, though it seems probable that flake blanks were used given the lack of evidence for an alternative reduction schema (Leakey et al., 1969).

The highest of the surface artefacts at the Living Site occurred immediately below the level of a 'pumiceous buff-green' tuff. An excavation was conducted in the Leakey Handaxe Area to determine the horizon from which the surface artefacts derived. This produced numerous artefacts below the tuff, featuring conjoins, although no bifaces or Levallois items (Leakey et al., 1969). Surface collections were made at the Factory site including of nine Levallois cores and two handaxes, one of which was found to refit back to its parent core. An excavation was conducted to determine the stratigraphic derivation of these artefacts, which produced a large Levallois core and flake within a clast rich horizon, estimated to be $\sim 10 \mathrm{~m}$ below the tuff identified at the Living Site (Blegen et al., 2018; Leakey et al., 1969). Subsequent work has established that the tuff in question is the Korosi Airfall Pumices dated to $395.6 \pm 3.5 \mathrm{ka}$, with both the Living Site and the Factory Site occurring in the upper part of the same geological member (K3), stratigraphically above the Lebus tuff dated to $465.3 \pm 1$ ka (Blegen et al., 2018).

In total, shaped tools and retouched pieces constitute $4.7 \%$ of artefacts from the Living Site, but just $0.9 \%$ of those from the Factory Site (Leakey et al., 1969). As their names indicate, the typological distinction between the two sites suggests the Living Site was a habitation area and the Factory Site a workshop, the latter making use of the boulders among which the in situ artefacts occur. This dichotomy in large site types is widespread in the Acheulean, representing the beginning and end points of handaxe and cleaver reduction within the same broad lifeway (e.g. Shipton et al., 2018a). While the height difference between the sites may indicate they were not occupied contemporaneously, they both fall within the same stratigraphic window (Blegen et al., 2018; Tallon, 1978), and they belong to the same tradition in which, unusually, large Levallois cores were used to make handaxe and cleaver blanks (Gowlett, 1999; Leakey et al., 1969; McBrearty, 1999). A noteworthy feature of the knapping technology at both the Living Site and the Factory Site is the systematic production of blades (Leakey et al., 1969), with conjoins and refitting pieces from the former, including the excavation (Cornelissen, 1992; Gowlett, 1990; McBrearty, 1999, 2001). Interestingly, blade cores 
show the opposite pattern to Levallois cores, only occurring at the Living Site, with the smaller size of the blade cores (Leakey et al., 1969: 65), suggesting they were a curated artefact type.

The artefacts analysed here are currently housed in the National Museum of Kenya and all available undamaged shaped handaxes and cleavers, and Levallois cores and flakes were used in this study. As much of the shaping of the large cutting tools from these sites was done on the core rather than as retouch, they do not fit comfortably under the umbrella term of Acheulean biface. They are referred to variously as ovate handaxes, 'unifaces', and bifaces, even within the same paper (McBrearty, 1999: 150). Of the 18 specimens classified in this study as handaxes or cleavers, 6 only have retouch on the dorsal surface, and 2 were not retouched at all (Fig. 2). However, their morphology of shaped elongate symmetrical tools with relatively thick butts and thin tips, having a tear-drop shape for handaxes and a broad bit at the tip for cleavers is consistent with other Acheulean assemblages. The original collectors saw these artefacts as handaxes and cleavers (Leakey et al., 1969), and previous morphometric analysis has shown these specimens display similar patterns in shape variation to older Acheulean assemblages in the region, such as Kariandusi (Gowlett \& Crompton, 1994) and Kalambo Falls (Gowlett et al., 2001). While a dearth of ventral retouch is unusual in the Acheulean, they also share this trait with the obsidian handaxes from Kariandusi (Gowlett \& Crompton, 1994: 24), and some cleavers from the late Acheulean site of Kalambo Falls (Fig. 3).

Where the retouch on handaxes and cleavers is more extensive, it is consistent with the Acheulean elsewhere, with bifacial flaking and more invasive scars to remove the thick bulb of the flake blank, followed by more marginal scars to impose a regular symmetrical plan form (e.g. de la Torre et al., 2014; Sharon, 2007; Shipton et al., 2018b) (Fig. 4). On cleavers the marginal flaking is not to create a cutting edge and it may even have functioned to increase the ergonomic properties of these tools, so it usually leaves a steep, scraper-like edge angle (Fig. 4).

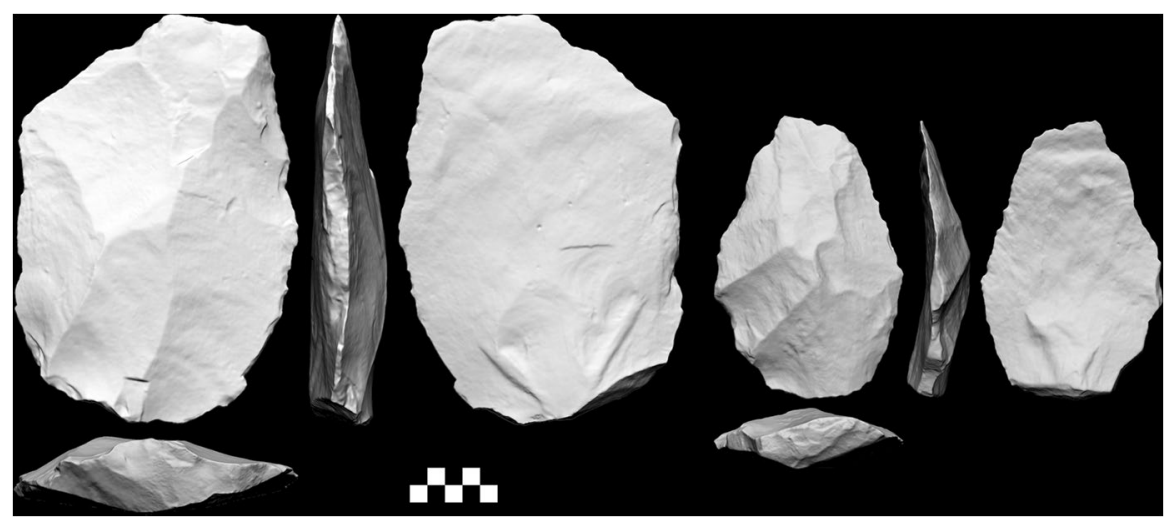

Fig. 2 Cleaver (left) and handaxe (right) Levallois flake 'blanks' from the Kapthurin Formation Leakey Handaxe Area. Note the centripetal dorsal scar patterns, facetted platforms, and elongation. Scale in $\mathrm{cm}$ 


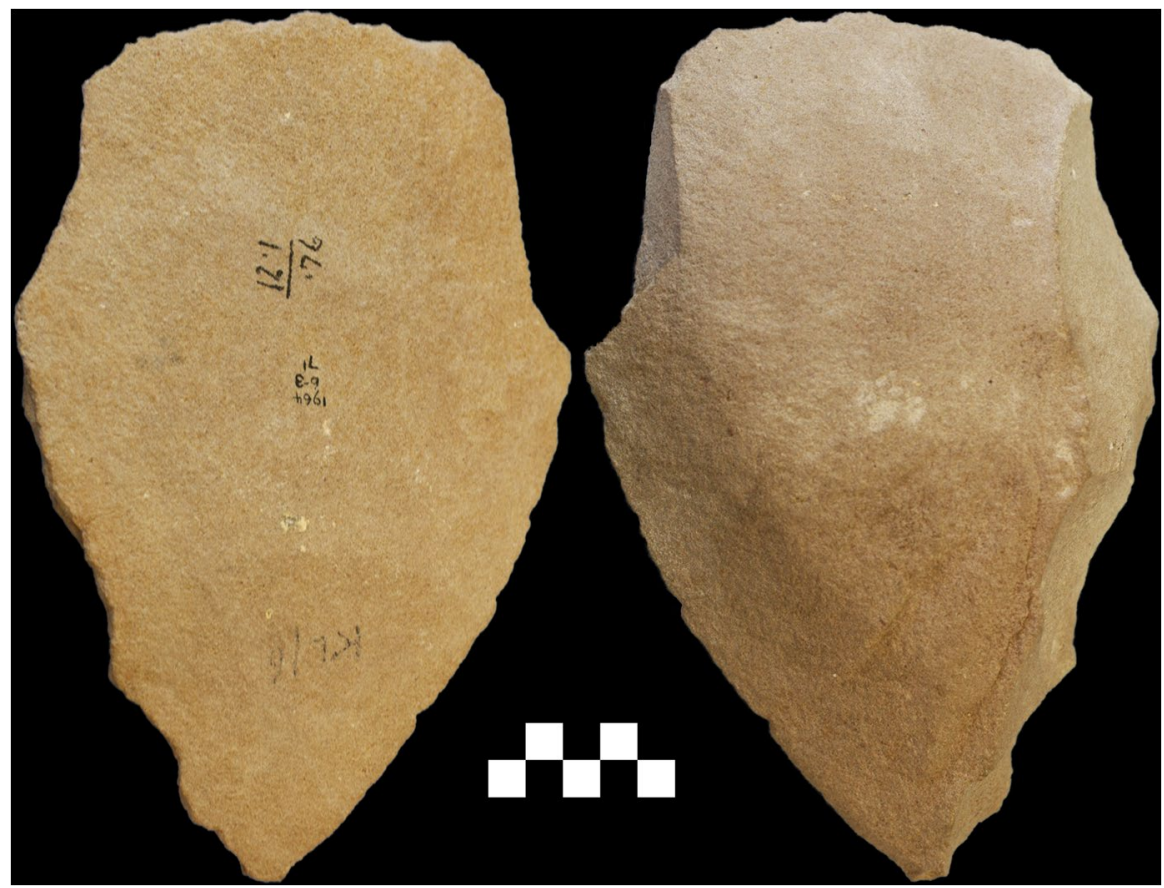

Fig. 3 Side-struck Janus flake cleaver from Kalambo Falls with no retouch on either the dorsal or ventral surfaces. There are some scars on the platform that may have been removed after the flake blank itself but none of these modify the ventral. Scale in $\mathrm{cm}$

The sample obtained here consists of 12 handaxes and cleavers and a Levallois core and flake from the Leakey Handaxe Area, and a further 7 handaxes and cleavers from the wider Living Site. From the Factory Site, 7 Levallois cores and 3 Levallois flakes were available, including one of each from the excavation. All handaxes and cleavers in the assemblage were made on flakes (Leakey et al., 1969), but a single handaxe was entirely covered in negative scars so it was not possible to tell the blank-in any case this was not included in the study because the tip was missing. All specimens were made on a fine-grained phonolitic lava which is available as rounded cobbles and boulders in the vicinity of the localities (Leakey et al., 1969; Tryon et al., 2005). Judging from the remaining cortex, initial clast sizes were rounded cobbles which could exceed $200 \times 150 \times 150 \mathrm{~mm}$, while experimental knapping by Pierre-Jean Texier indicates clasts of $10-15 \mathrm{~kg}$ are required to produce these large Levallois cores (McBrearty, 1999).

\section{Comparative Assemblages}

Systematic large flake production for the creation of handaxes and cleavers is a widespread phenomenon in the Acheulean (Leakey, 1931; Sharon, 2007), occurring in east Africa since at least $1330 \mathrm{ka}$ at Olduvai Gorge EF-HR (de la Torre \& 


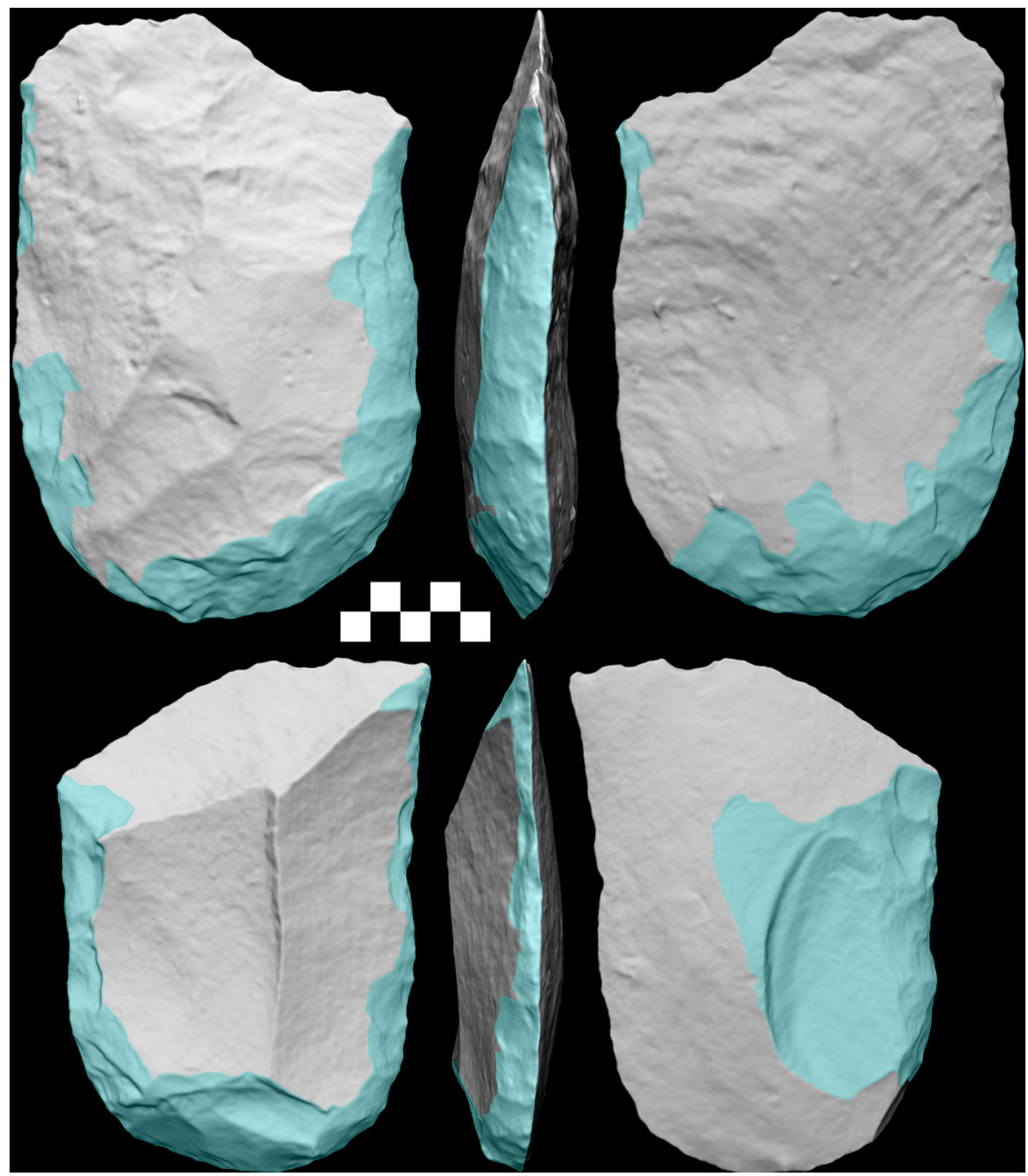

Fig. 4 Two cleavers from the Kapthurin Formation with relatively extensive retouch. Note that the more invasive scars remove the bulb of the flake blank, while the more marginal scars create a symmetrical, regular, and steeply bevelled lateral edge. Note also the particularly invasive retouch on the side-struck lower piece to remove the bulb of percussion. Scale in $\mathrm{cm}$

Mora, 2018) (Fig. 1), and from a similar time at Rietputs 15 in southern Africa (Leader et al., 2018). Previous studies have noted that the large flakes used to make handaxes and cleavers from the Living Site were struck from prepared cores (Leakey et al., 1969), in particular Levallois cores (Tryon et al., 2005). In the present study handaxes and cleavers made on large flakes are compared between multiple east African Acheulean sites to understand how the products of the Kapthurin Levallois technique differ from those of other methods of producing large flake blanks. 
The comparative material consists of random samples of flake-made handaxes and cleavers from four classic Acheulean assemblages in the central Rift Valley: Kariandusi, Olorgesailie CL1-1, Olorgesailie Member 6/7, and Isinya (Fig. 1) (Table 1). Similar to those of the Kapthurin Formation the handaxes and cleavers from these sites were all made on fine-grained volcanic rock. Farther south in the Rift Valley, Kalambo Falls (Fig. 1) was sampled as an example of a late Acheulean east African assemblage, and here handaxes and cleavers were made on quartzite. None of these comparative assemblages have evidence of Levallois technology in the creation of handaxe and cleaver blanks.

Kariandusi is a 960-780-ka-old site (Durkee \& Brown, 2014), with handaxes and cleavers made on trachyte, phonolite, and obsidian, including 5 specimens of the latter material in the present sample (Gowlett \& Crompton, 1994; Shipton, 2011). Olorgesailie CL1-1 is on current evidence the oldest sample in the study dated to 1100-992 ka (Owen et al., 2008). Here, an assemblage consisting entirely of lava flake blank bifaces was dominated by cleavers (Table 1). Olorgesailie Member 6/7 (localities DE/89, Meng, and Mid) dates to $960 \mathrm{ka}$ (Durkee \& Brown, 2014). Handaxes and cleavers from Member 6/7 were made on large flakes of trachyte, phonolite, and basalt (Isaac \& Isaac, 1977; Noll, 2000). Artefacts in the Isinya sequence may occur below the $960 \mathrm{ka}$ tuff identified in the Olorgesailie sequence (Durkee \& Brown, 2014), but this connection is based on major element composition only (Sano et al., 2020) and it could alternatively be from the same volcano but not the same eruption. On biostratigraphic grounds Isinya is contemporary with site HEB in Olduvai Bed IV (Brugal \& Denys, 1989) dated to < 800 ka (Njau et al., 2020). Handaxes and cleavers from Isinya were made on large flakes of phonolite (Roche et al., 1988). Kalambo Falls has a late Acheulean and early Middle Stone Age sequence (Clark et al., 2001) in which handaxes and cleavers were made on large flakes struck from quartzite boulder discoidal cores (Toth, 2001). The Acheulean part of the sequence at Kalambo Falls Site C has been dated to 500-300 ka (Duller et al., 2015), with a combined age estimate of $419 \pm 68$ ka (Barham et al., 2015). The artefacts analysed here derive from the 'final Acheulean' horizons near the base of the Site A sequence, likely also falling within the same timeframe as Site C (Clark et al., 2001).

Specimens were randomly selected (using the random number generator on a calculator) as a proportion of pieces within each drawer or box in which they were

Table 1 Breakdown of handaxes and cleavers used in this study by assemblage

\begin{tabular}{lllllll}
$\begin{array}{l}\text { Kapthurin } \\
\text { Living Site }\end{array}$ & $\begin{array}{l}\text { Kalambo } \\
\text { Falls A }\end{array}$ & Isinya & Kariandusi & $\begin{array}{l}\text { Olorgesailie } \\
\text { Member 6/7 }\end{array}$ & $\begin{array}{l}\text { Olorge- } \\
\text { sailie } \\
\text { CL1-1 }\end{array}$ & Total \\
430 & 419 & $<800$ & 870 & 960 & 1046 & N/A \\
7 & 3 & 6 & 30 & 4 & 3 & 53 \\
11 & 12 & 16 & 10 & 16 & 23 & 88 \\
18 & 15 & 22 & 40 & 20 & 26 & 143 \\
\hline
\end{tabular}


housed, depending on the total size of the collection available. Pieces that were extensively damaged were excluded. For further details on comparative sample selection see Shipton (2018), Shipton et al. (2018a)). Only specimens with an unambiguous ventral surface were included in this study as most assemblages also feature some handaxes and cleavers that were not made on large flakes.

To situate the Levallois cores in a comparative context, core length and preferential scar length were taken on Levallois cores from the unpublished dominated MSA surface site of Nyogonyek in the Kapthurin Formation (Tryon, 2002). Further comparative data on MSA Levallois core assemblages from the east African sites of Aduma A5 and Omo Kibish BNS was obtained from Blinkhorn et al. (2021). All of these comparative assemblages are dominated by centripetal Levallois preparation, and with exception of the chert dominated BNS assemblage they are also made on lava.

\section{Method}

Shaped tools were assigned a typology: handaxe or cleaver. Where evident the following variables relating to the flake blank were recorded: its orientation relative to the shaped tool (side, corner, or end -struck); its platform type (cortical, single, dihedral, multiple, facetted); and its scar pattern. Scar patterns were assigned to one of the following five categories: proximal, bidirectional (proximal and distal), orthogonal (scars originating from the direction of one or both lateral margins), centripetal (scars originating from four different directions), and Janus (flakes with two ventral surfaces) (e.g. Figure 3). The number of these remnant flake blank dorsal scars and the number of retouch scars larger than $5 \mathrm{~mm}$ on each surface of the tools were counted separately. The length of the largest retouch scar was measured along the percussion axis from its termination to the edge of the piece. Finishing order was recorded as alternating if flake scars with intact initiations were present on both surfaces, and dorsal or ventral last if these were only present on one surface.

3D models of handaxes and cleavers were made using a NextEngine laser scanner. In the program ScanStudio, models were oriented to maximise the symmetry of the longest sides and to minimise the tilt of the longest axis. Screenshots of the base of the artefact in this orientation were used to measure section asymmetry in the FlipTest program (Hardaker \& Dunn, 2005).

In the program Rapidworks the following variables were measured on oriented 3D models: box (axial) length, width, and thickness; volume; surface area; the angle of the tip; and where possible the platform angle of the flake blank (Fig. 5). Platform angle was measured from the initiation point to the platform edge orthogonal to the axis of percussion and then to the equivalent distance on to the dorsal surface. Tip angle was measured as the angle between the midpoint of the central scar on each surface along a line running around $4 / 5^{\text {ths }}$ of the tool length and the distal tip edge in the above orientation. Cutting edge length was measured between the edges of the bit for cleavers. For handaxes, cutting edge length was estimated as the sum on both lateral margins of the distance from the 


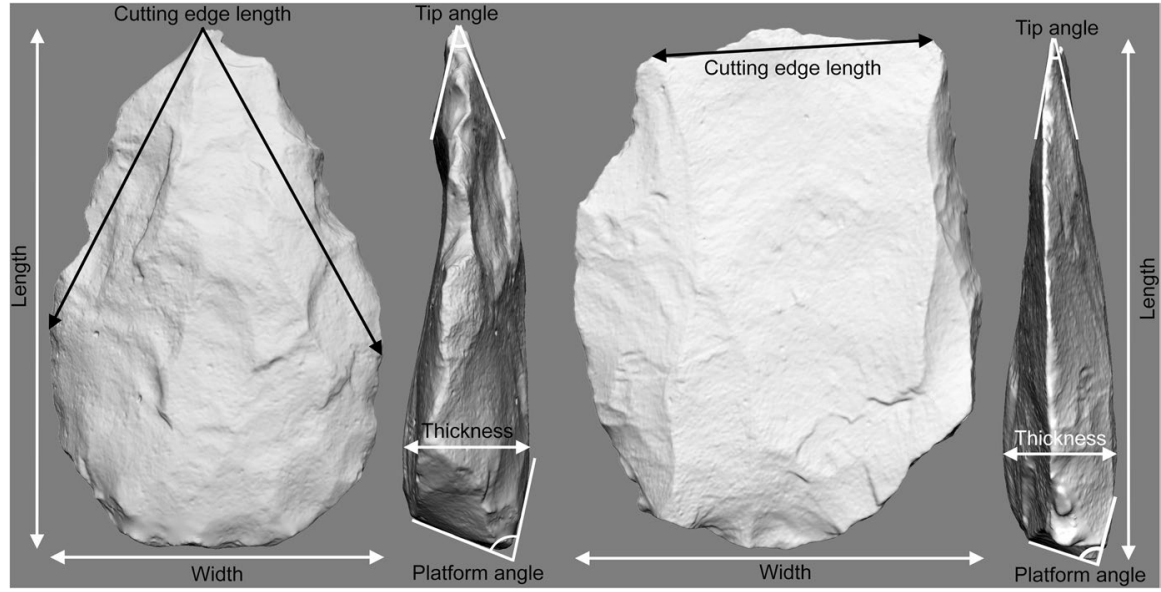

Fig. 5 Measurement protocols shown on a handaxe (left) and cleaver (right) from the Kapthurin Formation

distal tip to the point of maximum breadth, the 'forward extension' that provides support for the 'working edge' in the generalized design of Acheulean handaxes (Gowlett, 2006).

Using the above measured variables, a series of indices were calculated. The refinement and elongation indices were obtained by dividing thickness and length by width respectively (Roe, 1994). Two scar density index (SDI) values (Clarkson, 2013; Shipton \& Clarkson, 2015) were calculated. A ventral retouch SDI (Shipton, 2011) was estimated by dividing the number of scars on the ventral surface by half the surface area value, and a dorsal preparation SDI was estimated by dividing the total number of remnant dorsal scars by half the surface area value. An index of retouch flaking invasiveness was obtained by dividing the length of the longest retouch scar by the overall length of the tool to control for different sized pieces. In the sample as a whole, cutting edges as measured according to the above protocol were three times as long for handaxes as they were for cleavers, so to assess the two tool types in a single index of efficiency, cleaver bit length or 1/3 of handaxe cutting edge length was divided by weight.

Some similar variables were measured in a larger sample $(n=84)$ of handaxes and cleavers from Kariandusi (Gowlett \& Crompton, 1994: 21), allowing for an assessment of sample representativeness. A t-test showed that mean width to length ratio, which, unlike thickness to width ratio (Shipton, 2018; Shipton et al., 2018a), should not be particularly affected by blank type, was comparable between the two samples $(t=0.8324, \mathrm{df}=122, \mathrm{p}=0.4068)$. Likewise, the mean width to length ratio for all the bifaces excavated from the basal Acheulean horizon (VI) of Kalambo Falls site A $(n=48)$ (Roe, 2001: 567), was comparable to those in this sample $(t=0.7912$, $\mathrm{df}=61, p=0.419)$. Kolmogorov-Smirnov tests detailed below indicated all variables were normally distributed or were able to be transformed to be so. ANOVA tests indicate samples were large enough to demonstrate both commonalities between the comparative assemblages and differences with the Kapthurin Formation. 
In addition to the above variables on handaxes and cleavers, the Levallois cores and flakes also had their flake scars counted and were scanned in the same way. Orientation of the cores was according to the percussion axis of the final preferential removal (length) and minimising the tilt of the plane of intersection between the two hemispheres. Box (axial) length and the length of the preferential scar were measured on the cores in this orientation. Platform angle was measured between the midpoint (in the length plane) of the preferential scar, the initiation point, and the scar below the initiation point on the platform.

Statistical analysis was performed in SPSS v.27 (IBM, 2019). Variables were checked for normality using Kolmogorov-Smirnov (K-S) tests. Comparisons of variables across the assemblages were made with ANOVA tests, with post-hoc LSD tests for comparisons between individual assemblages. Pairwise comparisons of groups were made with t-tests for handaxes and cleavers, and, due to the low sample size, with Mann-Whitney U tests for Levallois cores.

\section{Handaxe and Cleaver Comparison}

The Living Site handaxes and cleavers stand out from the other assemblages in their relative width, being both the most refined and the least elongate (Fig. 6). Both these variables were normally distributed (refinement $\mathrm{K}-\mathrm{S}=0.53$, $\mathrm{df}=140$, $\mathrm{p} \geq 0.2$; elongation $\mathrm{K}-\mathrm{S}=0.5, \mathrm{df}=140, p \geq 0.2$ ). An ANOVA test indicated significant heterogeneity between sites for both variables (refinement $F=14.502$, df $=139$, $p<0.001$; elongation $F=10.377, \mathrm{df}=139, p<0.001$ ), with the post-hoc LSD tests showing that the Living Site pieces were significantly different from all other sites at $\mathrm{p}<0.001$.

Thinner handaxes and cleavers may afford more acute tip angles with sharper edges. Tip angle was transformed to normality by taking its square root (root tip angle $\mathrm{K}-\mathrm{S}=0.063, \mathrm{df}=138, p \geq 0.2)$, but an ANOVA $(F=3.118, \mathrm{df}=137, p=0.011)$ and LSD tests showed the only significant difference from the Living Site was with Olorgesailie CL1-1 ( $p=0.008)$. Indeed, Olorgesailie CL1-1 had significantly higher tip angles than all other assemblages except Olorgesailie Member 6/7 at the $p=0.02$ level.

Thinner, less elongate handaxes and cleavers may have longer cutting edges for their weight. The combined handaxe and cleaver cutting edge to weight efficiency index was transformed to normality by taking its square root $(\mathrm{K}-\mathrm{S}=0.053, \mathrm{df}=135$, $p \geq 0.2$ ). An ANOVA and LSD tests indicated significant heterogeneity in this variable $(F=7.345$, df $=134, p<0.001)$, with Living Site handaxes and cleavers having longer cutting edges relative to weight than all other assemblages at $p<0.001$, except Kariandusi, which they were longer than at $p=0.07$.

In addition to their form, the Living Site handaxes and cleavers are distinguished in their flake blank preparation (Fig. 2). Dorsal scar patterns are typically centripetal (17/18) (Fig. 7), with only 5/78 instances of centripetal scar patterns in the comparative sample. The flake blank SDI estimate was transformed to normality by taking its natural $\log (\mathrm{K}-\mathrm{S}=0.67, \mathrm{df}=143, p \geq 0.2)$. An ANOVA $(F=16.225, \mathrm{df}=142$, 


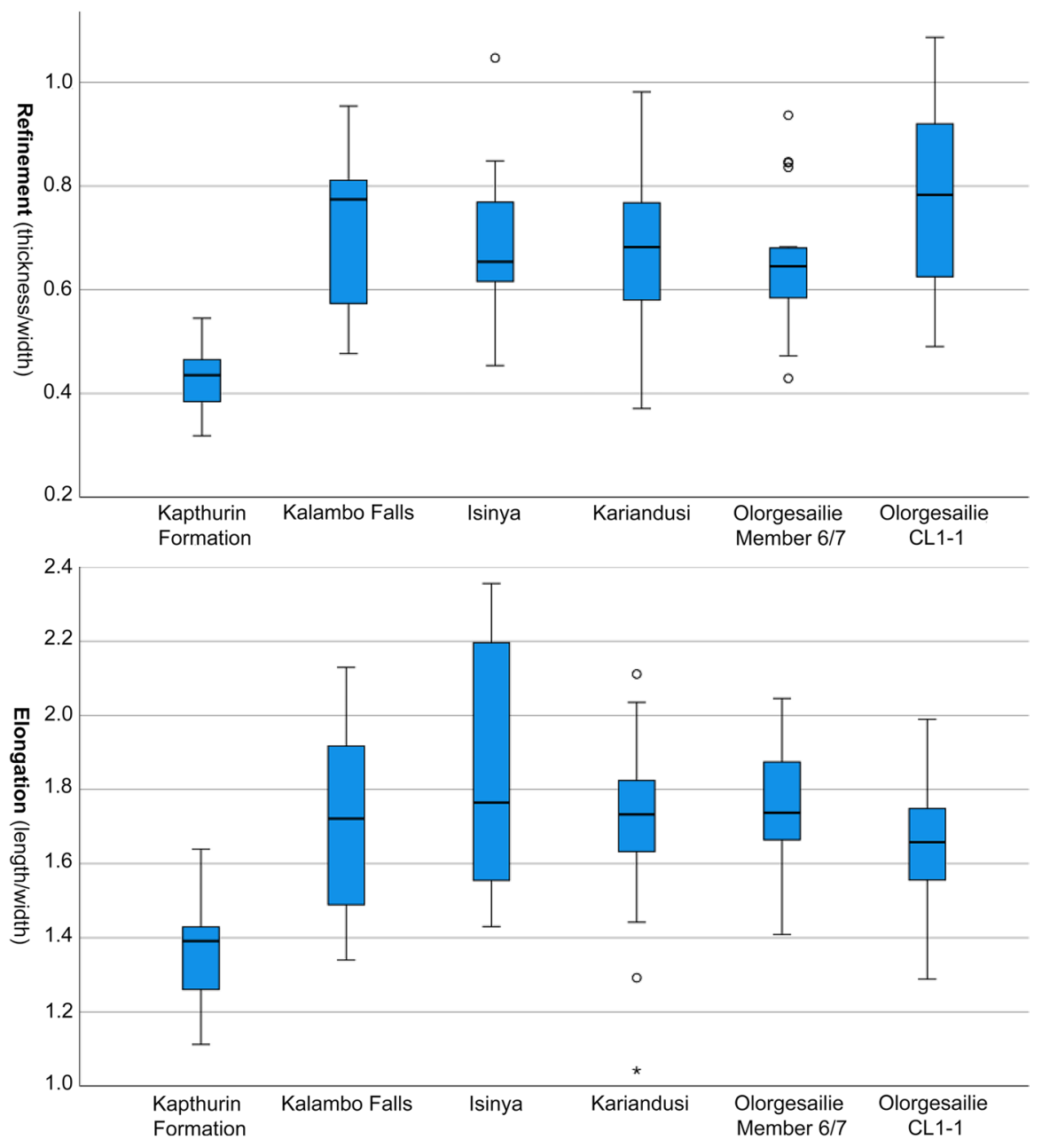

Fig. 6 Refinement (thickness to width ratio) and elongation (length to width ratio) of some east African flake biface assemblages

$p<0.001)$ and LSD tests showed that the Kapthurin specimens had significantly greater flake blank dorsal scar densities than all other assemblages at $p<0.001$.

Preparatory flaking of the main core surface influences the morphology of the preferential flake. Being able to flake the core from multiple directions allows for more control of this preparatory process. On flake cleavers the bit is invariably formed from the intersection between a preparatory dorsal scar and the ventral surface. To determine if there were significant differences resulting from core preparation, cleaver tip angles $(\mathrm{K}-\mathrm{S}=0.081, \mathrm{df}=88, p \geq 0.2)$ were compared between cortical and proximal dorsal scar patterns where flaking of the core is only from one direction, versus bidirectional, orthogonal, and centripetal scar patterns, where flaking is from multiple directions. There was a significant difference in tip angles 


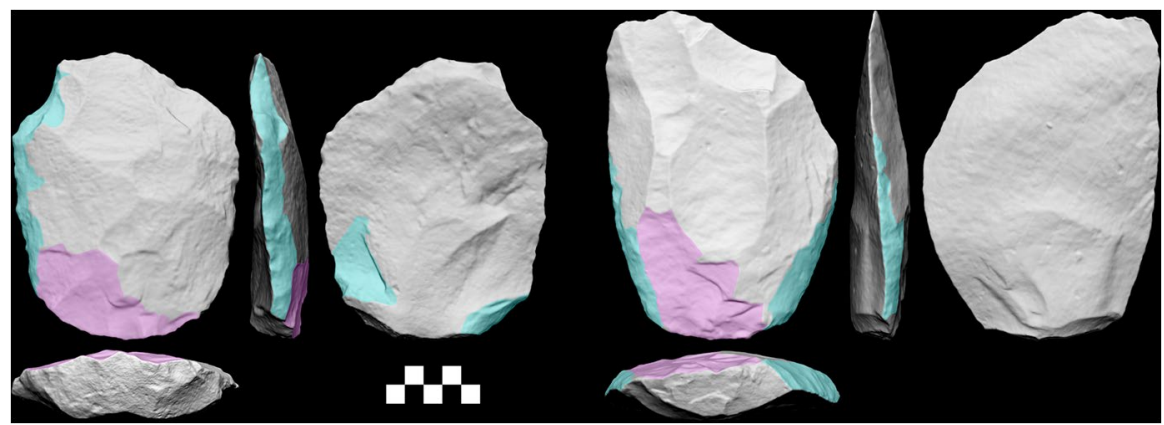

Fig. 7 Two large cleavers from the Kapthurin Formation Leakey Handaxe Area. Note the centripetal dorsal scar patterns, proximal bevelling (shown in pink), the convex facetted platforms, the alignment of the percussion axis to the finished tool, and the retouch (shown in blue) which is marginal and concentrated on the dorsal. Scale in $\mathrm{cm}$

between the two groups ( $t=2.676, \mathrm{df}=86, p=0.009$ ) suggesting flaking from multiple directions facilitates the creation of more gentle convexities on the dorsal surface of very large cores. An alternative method of creating gentle convexities that was widely practised in the Acheulean was to use the gentle dome of the ventral surface of a very large flake as the preferential flaking surface (Sharon, 2009). T-tests (using both handaxes and cleavers to increase sample size) showed no significant difference between the tip angles of the resulting Janus flakes and those with preparation from multiple directions $(t=0.283, \mathrm{df}=72, p=0.778)$, but a significant difference between Janus flakes and blanks flaked from a single direction $(t=2.137, \mathrm{df}=35$ $p=0.04)$.

In order to strike large preferential flakes, it is necessary for Levallois flake platforms to sit relatively deep in the core. However, the resultant thick platform and bulb of percussion would make the overall Levallois flake thick. To counteract this, a strategy used by some Levallois knappers is to finish preparation of the upper surface with flakes that reduce mass on the proximal end of the core (bevelling (Leader et al., 2017)). This strategy is evident in the Living Site with removals struck from the proximal truncating lateral scars (Figs. 7, 8).

The Living Site flake blank platforms were usually facetted (13/16) (Figs. 6, 7, 8 ), but there are no examples of this trait in the comparative sample. The facetting on Living Site pieces is such that there is slight protrusion in plan view in the centre of the platform, to facilitate the placement of the preferential strike (Figs. 7, 8). The Living Site flake blanks were also usually (16/18) struck along the same axis as the finished tool (end-struck) (Figs. 6, 7, 8), with only 14/95 instances of this trait in the comparative sample. The other assemblage with a relatively high proportion (7/14) of end-struck blanks is Isinya, with Isinya and Kapthurin having the two highest median platform angles in the sample $\left(89^{\circ}\right.$ and $86^{\circ}$ respectively). Higher platform angles have been experimentally shown to produce more elongate flakes (Lin et al., 2013), so it may be that the production of elongate end-struck flake blanks is linked to having higher platform angles. Platform angle was normally distributed $(\mathrm{K}-\mathrm{S}=0.07, \mathrm{df}=42, p \geq 0.2)$, with a 
Fig. 8 Two handaxes (above) and a cleaver from the Kapthurin Formation. Note the proximal bevelling (shown in pink), the convex facetted platforms, the alignment of the percussion axis to that of the finished tool, and the retouch (shown in blue) which is marginal on the dorsal with few scars on the ventral. Scales in $\mathrm{cm}$

t-test showing significantly higher mean platform angles for end-struck $\left(85 \pm 15^{\circ}\right)$ than side-struck $\left(67 \pm 12^{\circ}\right)$ flakes $(t=4.134, \mathrm{df}=34, p<0.001)$ in the sample as a whole.

The management of convexities on all sides of the core through centripetal flaking, coupled with the striking the preferential flakes parallel to the axis of the finished tool probably explains another distinguishing feature of the Living Site handaxes and cleavers: Their symmetry in cross section (Fig. 9). This variable was transformed to normality by taking its square root $(\mathrm{K}-\mathrm{S}=0.059$, $\mathrm{df}=140$, $p \geq 0.2)$. An ANOVA $(F=0.827, \mathrm{df}=139, p=0.003)$ and LSD tests showed the Kapthurin Formation specimens had significantly more symmetrical sections than the other assemblages at $p<0.025$. Acheulean blank creation often targets a high topography lump resulting in a thick flake (Shipton, 2016), but with the creation of gentle convexities on both sides of a flaking surface a symmetrical large thin flake can be removed.

In contrast to the high flake blank scar densities, the Living Site handaxes and cleavers have little ventral retouch (Figs. 7, 8). The ventral SDI estimate was transformed to normality by taking its square root $(\mathrm{K}-\mathrm{S}=0.047, \mathrm{df}=141$, $p=0.58)$. An ANOVA $(F=11.383, \mathrm{df}=140, p<0.001)$ and LSD tests showed the Kapthurin handaxes and cleavers had significantly less ventral retouch scars than any other assemblage at $p=0.01$. For many side-struck blank bifaces, retouch on the ventral was done to remove the platform and the bulb of percussion to create a symmetrical tool (Shipton et al., 2018b), but this is not necessary in end-struck flakes (Shipton, 2016). The single example of a side-struck cleaver from the Kapthurin Formation showed the most invasive retouch in order to remove its bulb (Fig. 4). In the sample as a whole, platforms had been retouched away in 58/71 cases for side-struck flakes, compared with only 7/30 in end-struck flakes.

The retouch that there was on the Living Site handaxes and cleavers may be classed as marginal trimming rather than invasive shaping (Figs. 7, 8). The ratio of the longest retouch scar to biface length was normally distributed ( $\mathrm{K}-\mathrm{S}=0.062$, $\mathrm{df}=138, p \geq 0.2)$. An ANOVA indicated significant site-wise heterogeneity in this variable $(F=4.662, \mathrm{df}=137, p=0.001)$ with LSD tests showing the Kapthurin pieces have significantly smaller retouch scars than the other assemblages at $p=0.01$ (Fig. 9). Unlike the alternate flaking that characterizes most Acheulean biface shaping, the Living Site specimens were typically finished with dorsal removals (Figs. 7, 8). Final scars having intact initiations were limited to the dorsal surface in 10/16 cases for the Kapthurin specimens, compared with 124/127 instances of alternating finishing between the surfaces in the comparative sample. Dorsal only retouch on cleavers seems to have been to impose a steep edge suitable for gripping, as well as creating plan symmetry-often through mirroring an unretouched edge (Figs. 7, 8). 


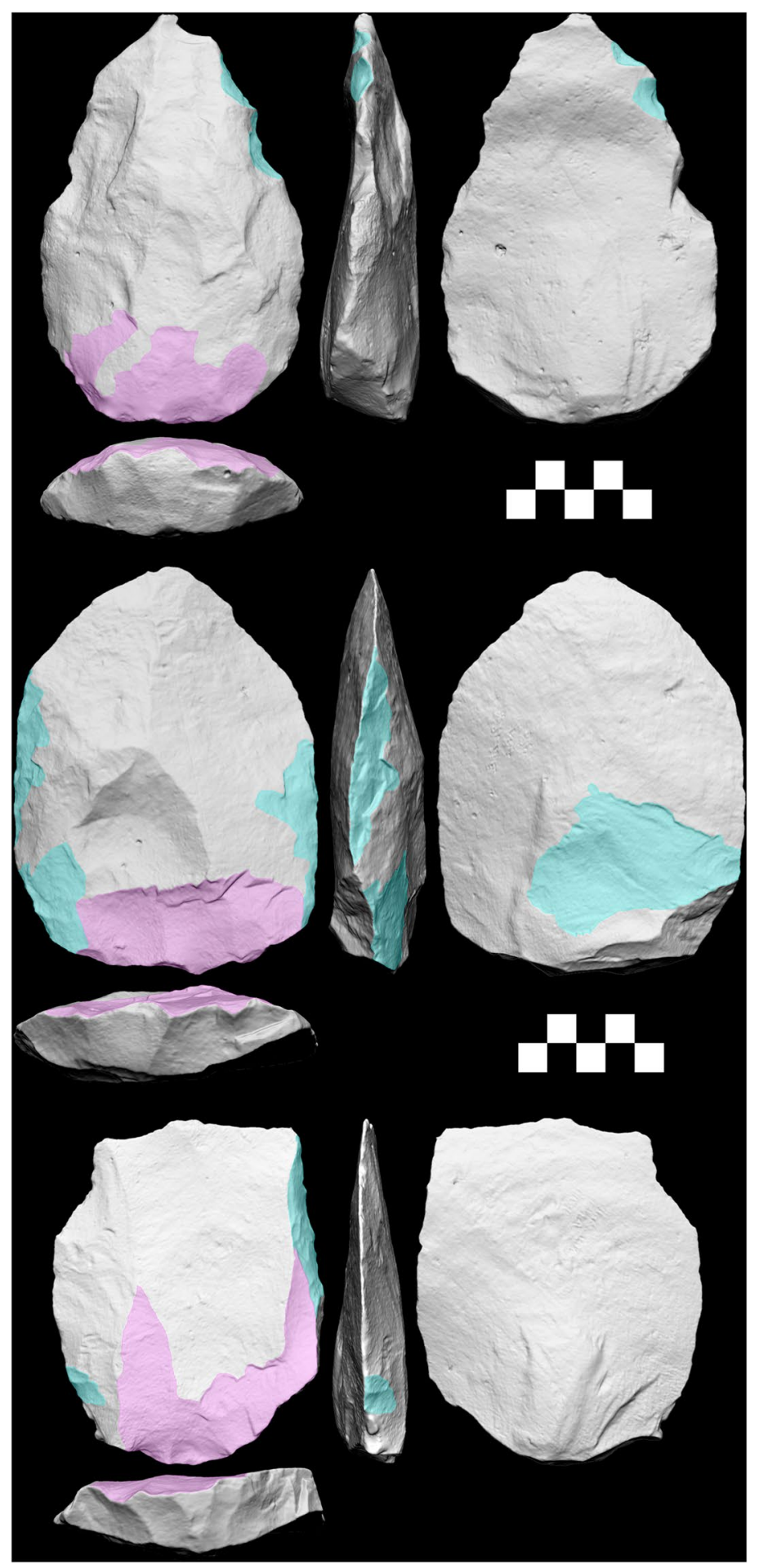



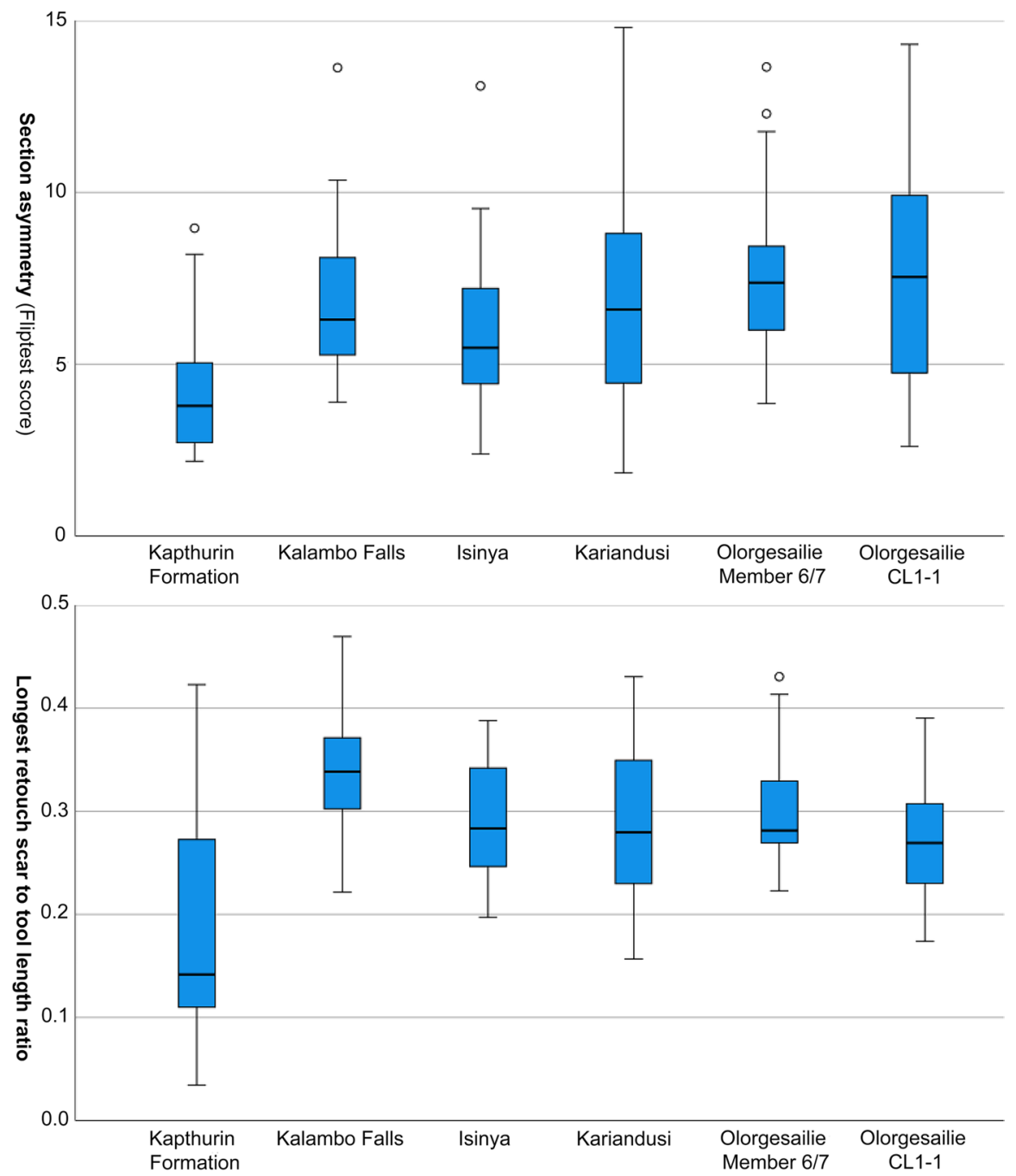

Fig. 9 Section asymmetry and longest retouch scar to biface length ratio for some flake blank east African biface assemblages. Asymmetry was measured using the FlipTest (Hardaker \& Dunn, 2005). Note that an outlier with a FlipTest score of 16.08 is not shown for Kalambo Falls and an outlier with a longest scar to biface length ratio of 0.61 is not shown for Kariandusi

\section{Levallois Comparison}

While they are unambiguously Levallois, the Acheulean cores of the Kapthurin Acheulean differ from those of the MSA (Tryon et al., 2005). Firstly, the Kapthurin Levallois cores are some of the largest in the world. Comparison with MSA centripetal Levallois core assemblages from east Africa and neighbouring regions shows the Kapthurin Acheulean specimens are over twice as long with preferential scars at least double the length (Table 2). The large size of the Acheulean Levallois cores 


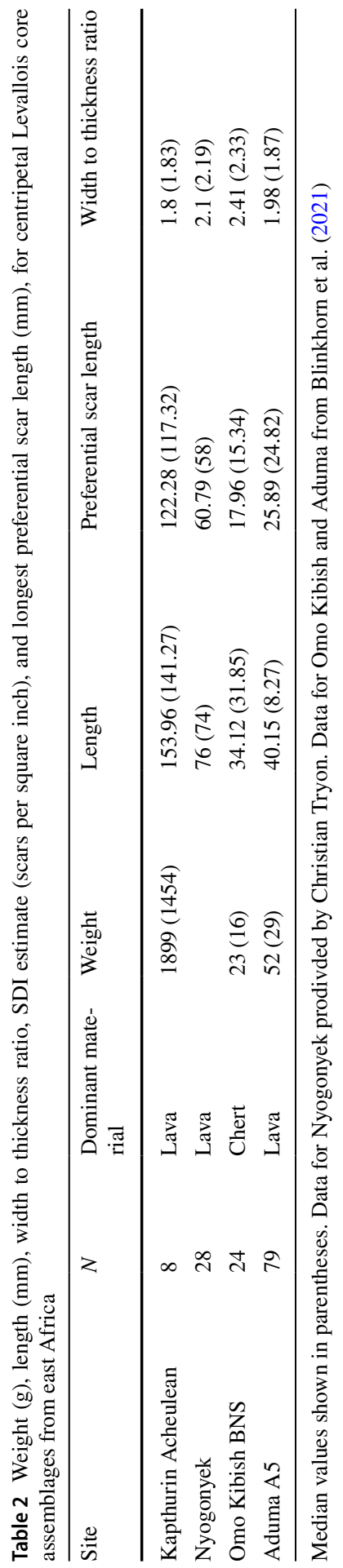


may in part be an effect of initial clast size (Tryon et al., 2008), or a lack of core curation, with the Factory Site pieces occurring within the large boulder conglomerate that provided the material. However, the Acheulean Kapthurin Levallois cores are still an order of magnitude heavier than Levallois cores from the Kapthurin early MSA site of Koimilot (Tryon et al., 2005) ( $3 \mathrm{~km}$ to the south of the Factory Site), where lava cobbles were similarly locally available (Tryon, 2006: 369). Indeed, a sample of lava Levallois cores from MSA sites in the Kapthurin Formation more generally had an average length of $\sim 80 \mathrm{~mm}$ (Tryon et al., 2008), half that of the Acheulean Levallois. Mann-Whitney U tests comparing core length and largest scar length between the Kapthurin Acheulean cores and the local MSA cores from Nyogonyek showed the size difference was significant (core length $U=0, n=28$, $p<0.001$; largest scar length $U=1, n=27, p<0.001$ ).

The extreme size of the Kapthurin Acheulean Levallois cores most likely reflects the fact that they were for creating handheld large shaped tools, whereas MSA Levallois cores were for creating smaller tools that were often hafted (e.g. Rots et al., 2011). The large size may also explain the focus on centripetal preparation (Figs. 6 and 10), rather than the diversity of modes seen in the MSA (Tryon et al., 2005): Shaping distal and lateral convexities and preparing a platform for a very large preferential flake requires flaking the surface from multiple margins. The diversity of MSA methods might also reflect a greater diversity of end-products rather than the two shaped tool types being created in the Acheulean.

Another characteristic feature of the Factory Site Levallois cores is the frequency of overshot flakes and cores. Overshooting is an unusual feature of MSA Levallois, with one of the most frequent known occurrences being from the Nubian assemblage of Abydos in Egypt, where 5\% of Levallois flakes were overshot (Chiotti et al., 2009). At the Kapthurin Factory Site 3/7 Levallois cores are overshot, and there are

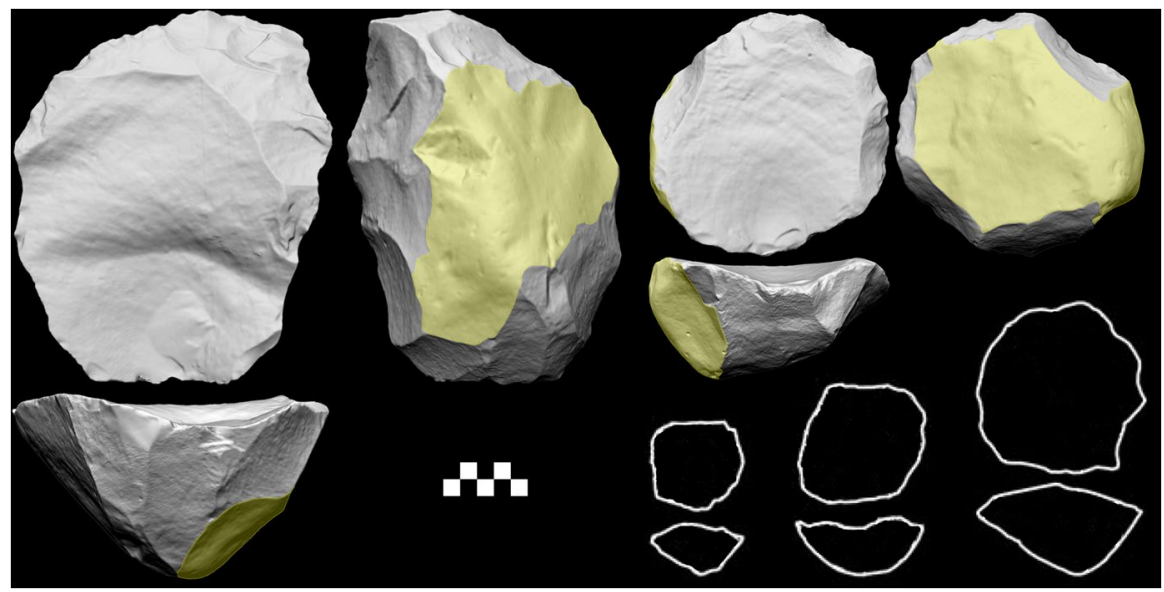

Fig. 10 Two Levallois cores from the Kapthurin Formation Leakey Factory Site, shown alongside outlines of centripetal prepared Levallois cores from the MSA site of Komilot (after: Tryon et al., 2005). Note the large size and centripetal preparation of the Leakey Factory Site cores. Cortex in yellow, scale in $\mathrm{cm}$ 


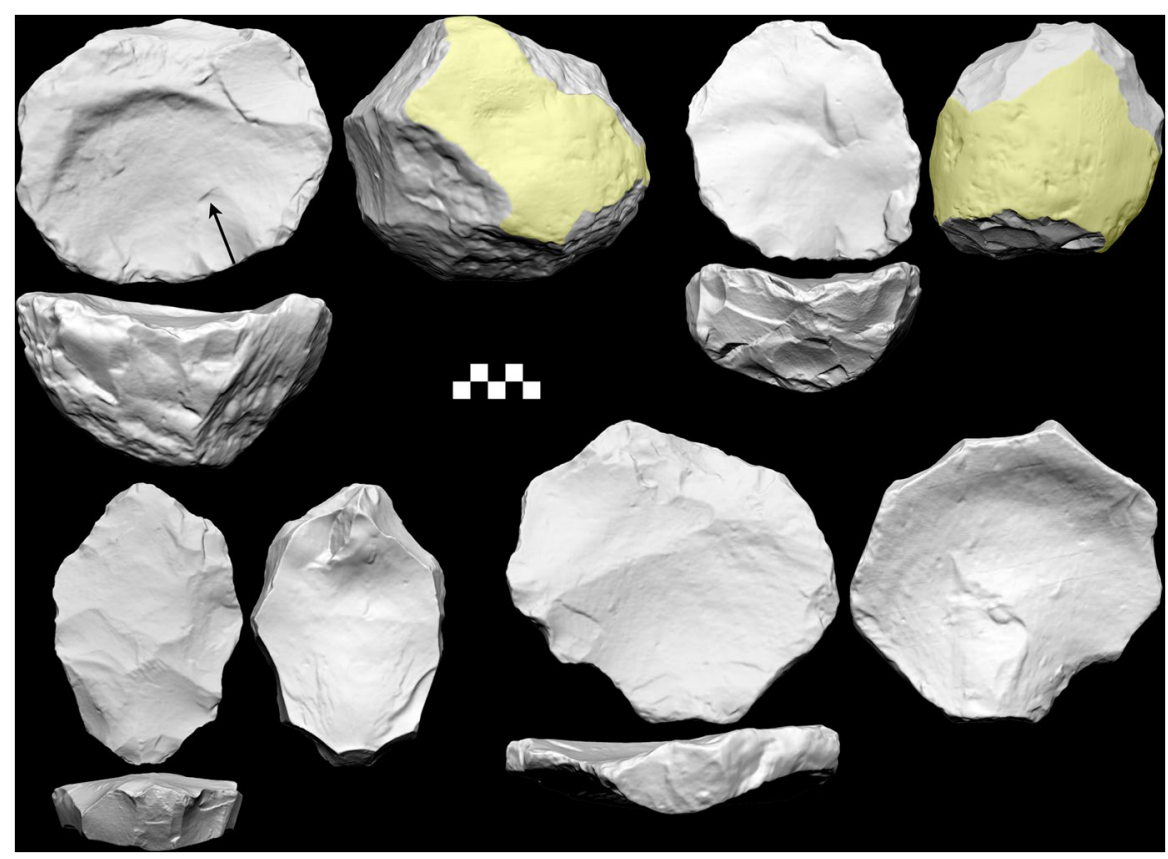

Fig. 11 Overshot Levallois cores (above) and flakes (below) from the Leakey Factory Site. Note on the specimen on the top left there is a final scar (shown by the arrow) truncating the overshot scar that was struck from the same platform. Cortex in yellow, scale in $\mathrm{cm}$

three further examples of overshot flakes (Figs. 11, 12). This is perhaps again related to the size of the cores with the need for very forceful strikes to produce the very large elongate flakes meaning there is less control over precisely how much force is used. A further overshot flake from the Leakey Handaxe Area supports this hypothesis: It has an incipient secondary bulb of percussion on its ventral surface where there was an attempt at a preferential removal, but the strike was not strong enough to detach the flake; the following overshot probably overcompensated for the failed strike (Fig. 13).

The unsuccessful overshot cores were abandoned without further attempts to flake them, despite the fact that all three cores had appropriate edge angles and enough material to produce more large flake blanks (Figs. 11, 12). In one case an overshot core had a single final removal struck after the overshot flake from the same platform, which travelled less than a third of the way across the surface and was not accompanied by any repreparation (Fig. 11).

Metric evidence further suggests these cores were being abandoned relatively prematurely. All eight Acheulean Levallois cores are considerably longer than the length of the smallest handaxe or cleaver $(84.6 \mathrm{~mm})$, with the shortest core measuring $112.57 \times 144.34 \mathrm{~mm}$. The three overshot cores measure 188,141 , and $130 \mathrm{~mm}$ long, even the smallest being longer than $4 / 18$ of the handaxes and cleavers. Mean and median platform angles after the preferential removal on the Kapthurin Acheulean Levallois cores were $76.5^{\circ}$ and $72^{\circ}$ respectively, ideally suited for further 


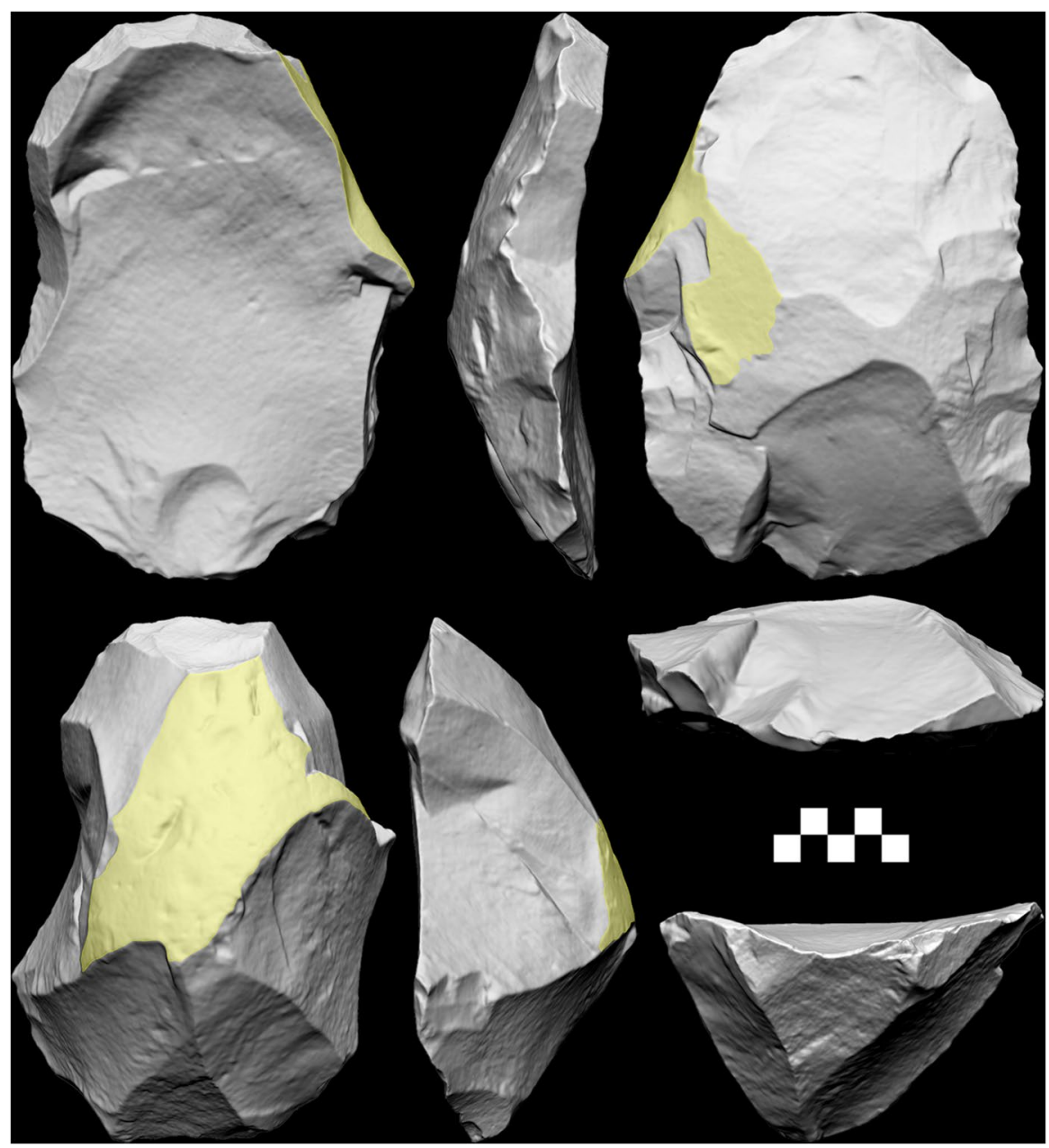

Fig. 12 Refitting overshot Levallois core (below) and flake (above) from the Leakey Factory Site. Cortex in yellow, scale in $\mathrm{cm}$

flaking. Mean and median core thickness to width ratios were 1.8 and 1.83 respectively, low for Levallois cores at the point of discard (Table 2) and indicating there was plenty of reduction potential left in these pieces (Brantingham \& Kuhn, 2001).

The hallmark of Levallois repreparation is the débordant flake, whereby the lateral convexities of a core are restored after a preferential strike by removals that run along the edge of the core. Débordants and the characteristic pattern they leave on cores of elongate lateral scars truncating a large central scar, were noted from the MSA Koimilot sites, but not the Kapthurin Acheulean (Tryon, 2006; Tryon et al., 2005). While 11 redirecting flakes (removing old platforms) were reported from the original fieldwork, these may relate to any of the 101 cores found at the sites (Leakey et al., 1969), not necessarily the large Levallois. Indeed, only two of these 


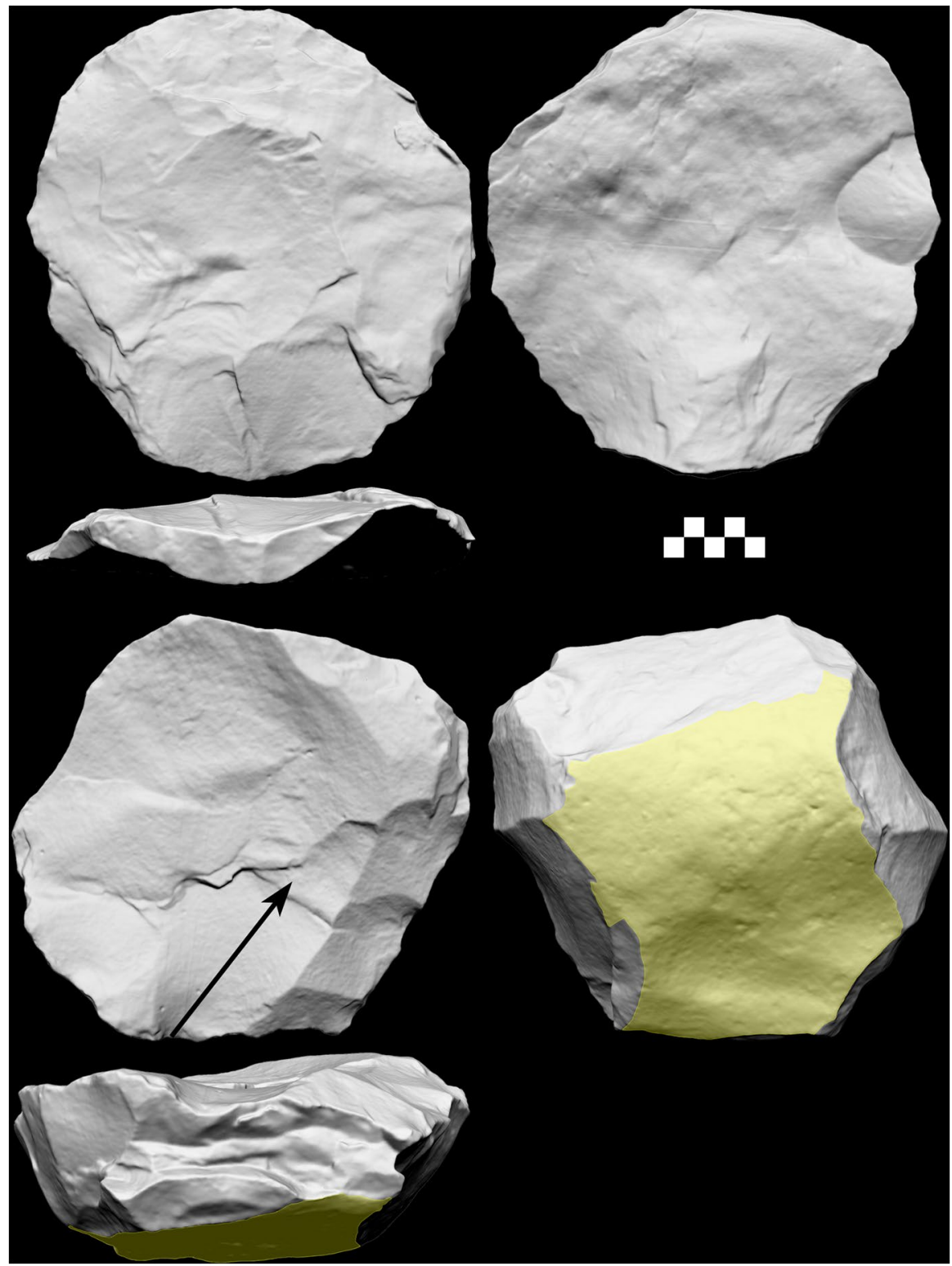

Fig. 13 Levallois core (below) and overshot flake (above) from the Leakey Handaxe Area. Note the second attempt at a preferential removal (shown by the arrow) from a different platform to the first on the core, and the incipient bulb from a failed strike on the right of the flake. Cortex in yellow, scale in $\mathrm{cm}$

redirecting flakes actually come from the Factory Site where nearly all the Levallois cores occur, and these both have cortex on them, suggesting they were probably not struck after an initial round of shaping a Levallois surface. None of the cores or the handaxes and cleavers from the Kapthurin Acheulean show a scar pattern that 
would be consistent with débordant preparation. A refitting Levallois core and flake from the Factory Site also suggests a lack of repreparation after a first preferential removal (Fig. 12). Despite still having plenty of material for another attempt, this core was abandoned after the overshooting preferential flake. And we can be certain that this was the first and only preferential flake, as there is a remnant patch of cortex on the centre left of its dorsal surface.

The removal of only a single preferential flake sets the Kapthurin Acheulean Levallois apart from that of the MSA (Tryon et al., 2005). Recurrent flaking, whereby several preferential flakes are removed in the same sequence, is characteristic of most MSA Levallois assemblages. At the early MSA Sibilo School Road Site, $10 \mathrm{~km}$ to the north of the Living Site, an assemblage of seven Levallois cores has been recovered with three showing evidence of recurrent flaking, including refitting of two repreparation flakes on one core and five preferential flakes on another (Blegen, 2017). The need for very large products (Tryon et al., 2005) and the cost of transporting such heavy cores may have discouraged the Kapthurin Acheulean knappers from recurrent flaking of their Levallois cores. Interestingly, the Levallois core that shows the clearest attempt at recurrent flaking is one that was transported to the Leakey Handaxe Area (Fig. 13). However, in this case the preferential surface had not been reprepared after the previous preferential flake removed much of the left lateral convexity, resulting in this final scar being too small for a handaxe or cleaver blank. This piece suggests that hominins were aware of the further reduction potential of these cores, but did not return to an earlier stage of production to rejuvenate them.

\section{Discussion}

From 300 to $50 \mathrm{ka}$, the knapping of MSA (or Middle Palaeolithic) hominins across Africa and much of Eurasia was characterized by the Levallois technique. However, one of the earliest manifestations of this complex technology was in the Acheulean of the Kapthurin Formation $400 \mathrm{ka}$. The products of the Kapthurin Acheulean Levallois knapping are instructive as to what this technology offers over other techniques for systematically creating large flake blanks, known from Acheulean sites from at least $1300 \mathrm{ka}$. Meanwhile, differences between the ESA Kapthurin Levallois and that of the MSA indicate critical distinctions between these two broad phases of hominin behaviour.

One of the most formal Acheulean large flake blank creation methods is that of Victoria West in southern Africa, dated to $1000 \mathrm{ka}$ at Canteen Kopje (Li et al., 2017). This technique has notable parallels with the Kapthurin Acheulean Levallois including hierarchically organized bifacial surfaces and shaping of convexities on the flatter upper surface through centripetal flaking. However, it differs in some important respects as well. For example, at Canteen Kopje the formal Victoria West cores are rare ( $<10 \%$ of the core assemblage) (Li et al., 2017), whereas in the Kapthurin Formation Acheulean nearly all the large cores and large shaped tools are Levallois. 
In the Kapthurin Formation much of the shaping seems to have been done on the massive Levallois cores rather than as retouch (Gowlett, 1984: 186). The Living Site handaxe and cleavers were consistently made on blanks with complex centripetal scar patterns, while there was very little retouch in comparison to other assemblages. Victoria West cleavers were similarly produced with centripetal preparatory shaping and very little retouch (Sharon \& Beaumont, 2006). One of the key differences between these technologies is the strike orientation relative to the axis of the finished tool. Integral to creating the end-struck flake blanks in the Kapthurin Formation seems to have been creating a strong (facetted) high angled platform. Achieving alignment between flake blank and finished tool axis meant the thickest part of the flake, the bulb and platform, formed the globular handaxe or cleaver butt (Gowlett, 2006), rather than occurring as an asymmetry on the side of the tool where they would need to be removed. Creating elongate flake blanks from high angled platforms was also done, albeit less frequently, at Isinya. The critical difference between other elongate blanks and those of the Living Site however, is the enhanced preparatory shaping of the latter; with gentle symmetrical lateral convexities and a protruding facetted platform to guide both the point of impact and the propagation of the preferential flake across the surface. To some extent this parallels the large flake blank creation method at the terminal Acheulean site of Bhimbetka in India, although there platform preparation was not used (Shipton, 2016). The resultant symmetrical, thin blanks of the Living Site typically required only marginal retouch in order to achieve their final form. Systematic blade production at the same sites suggests removing elongate pieces was part of the general knapping repertoire of these hominins (Leakey et al., 1969; McBrearty, 2001).

Throughout the Acheulean of east Africa and beyond, a goal of biface knappers seems to have been to create thin pieces (Shipton, 2018; Shipton et al., 2018a) (excepting the Sangoan core-axes of the final Acheulean). The proximal bevelling evident from the Living Site in handaxe and cleaver blank production indicates thin pieces were also important to the Kapthurin Acheulean knappers. By ensuring the platform and bulb aligned with the butt of the finished tool and by careful preparation of the lateral and distal convexities on the Levallois cores, the Kapthurin Acheulean knappers were able to create markedly thinner handaxes and cleavers than in other east African flake blank assemblages. Handaxe and cleaver refinement in the late Acheulean of the Kapthurin Formation can thus be said to have been predetermined by the Levallois technique for creating large elongate flat flakes.

Surprisingly, the overall thinness of the Kapthurin specimens does not translate into sharper tip angles, with all assemblages having comparable tip angles except the oldest (and thickest) assemblage: Olorgesailie CL1-1. Creating shallow tip angles was achieved in a variety of ways in the Acheulean, with flaking from multiple directions, or using the dome of a large ventral surface more effective than flaking from one direction only. Rather than sharper tips, the advantage of greater overall thinness for the Living Site specimens may instead lie in the costs of cutting-edge transport, with these pieces being wider for their weight than the other assemblages. Distinctively for an east African Acheulean assemblage (Shipton, 2020), the LHA handaxes and cleavers are not particularly elongate. This may reflect limitations in very large elongate end-struck flake blank creation from Levallois cores, with 
reduced length compensated for by greater width to maintain cutting edge length. This accords with the previous finding for handaxes and cleavers from both the Living Site and Kariandusi that larger specimens are overall narrower and thinner (perhaps to minimize weight), but have relatively wide tips (and therefore long cutting edges) (Gowlett \& Crompton, 1994).

The Acheulean Levallois of the Kapthurin Formation differs from that of the MSA both here and more generally in four respects: it is much larger; it has a lower diversity of preparation techniques; overshot errors are much more frequent; and only one preferential flake seems to have been produced per reduction sequence (i.e. there was no recurrent flaking). The large size of the Levallois cores may be explained by the large cutting tool end products. The need to shape large surfaces from multiple directions probably also partly explains the centripetal flaking patterns, while the extreme force required to strike very large Levallois flakes seems to have often resulted in overshots. Although the flatness of Levallois flakes was later used to facilitate hafting in the MSA, the large size and lack of hafting traces or modifications indicates that these handaxes and cleavers, were, like their predecessors, handheld. This early example of the hierarchically complex Levallois technique (Muller et al., 2017) thus appears to predate hafting in east Africa (e.g. Sahle et al., 2013), which is perhaps unsurprising given the even greater extremes of hierarchical complexity required for hafting (Lombard \& Haidle, 2012).

The lack of recurrent flaking on the same surface of the Kapthurin Acheulean Levallois cores may be explained by the need for only a single large flake. However, there was also apparently a lack of repreparation of the dorsal convexities once the first preferential flake had been struck, even if the core was still large enough for further work, and even if the preferential flake was unsuccessful (overshot). Similar, single-use cores were also a feature of large flake blank production in the Victoria West industry (Li et al., 2017) and the Acheulean Levallois at Amane Oukider (Arzarello et al., 2012). Acheulean knappers seem to have moved through unidirectionally organized stages in their flake blank creation, just as façonnage handaxe knapping proceeds from roughing out, to shaping, to thinning, to marginal trimming (Newcomer, 1971). In the MSA by contrast, débordant and other repreparation flakes allow for a return to an earlier stage of the Levallois process and the creation of a renewed preferential surface. Part of the explanation for this, and the greater diversity of preparation techniques noted in the MSA (Tryon et al., 2005), may be the greater diversity of end-products: Rather than two types of shaped tool, MSA Levallois has been characterized as 'the toolkit within the core' (Shimelmitz \& Kuhn, 2018). Systematic blade production at the Living Site also suggests these hominins may have been shifting away from individual large portable ergonomic tools, to portable toolkits. A parallel may be drawn with the final Acheulean industries in the Levant and India, where the frequency of handaxes and cleavers drops off when small prepared cores become part of the assemblages (Jagher, 2016; Shipton et al., 2013).

The hierarchical complexity of Acheulean knapping reached a peak in the last $500 \mathrm{ka}$, evidenced by Levallois flake blank production in the Kapthurin Formation, or by platform faceting (Stout et al., 2014) and raising the plane of intersection at Boxgrove (Shipton, 2019: 342-347). These two assemblages are among the most 
refined Acheulean assemblages anywhere in the world, with increasing hominin encephalization over the course of the Acheulean perhaps affording these knappers the ability to attain the greatest heights of their craft (Shipton, 2013: 72-78). However, the lack of evidence for hafting suggests further hierarchical complexity integrating multiple materials was not part of their behavioural repertoire. Likewise, the emphasis on single end-products in the Acheulean Levallois knapping of both the Kapthurin Formation and Amane Oukider, contrasts with the diversity in individual MSA/Middle Palaeolithic Levallois sequences, suggesting an enhanced capacity to integrate multiple tasks in the latter. Widening of the frontal lobes and expansion of the parietal lobes in both the species associated with the MSA/Middle Palaeolithic, Neanderthals and Homo sapiens (Bruner, 2021), suggest changes in the frontal and parietal association cortices which integrate information from multiple brain regions (e.g. Jung et al., 2017). Such cognitive integration may have afforded these hominins greater capacity for integrating their technology with diverse aspects of their environments (Wragg Sykes, 2015).

In one sense the Kapthurin late Acheulean may be seen as the culmination of a trend for increasing refinement that is apparent during the Acheulean when looking across timescales of hundreds of thousands of years (Shipton, 2018; Shipton et al., 2018a). This assemblage also directly presages the quintessential technology of the subsequent MSA, with its predetermination of refined elongate flakes. Nonetheless, there was an important distinction between the two: The principal artefacts transported away from the primary manufacturing site were individual tools with long cutting edges in the Kapthurin Acheulean; whereas, in the MSA, smaller Levallois cores and the potential for a diverse toolkit characterize artefact transport, sometimes over much longer distances than in the Acheulean (Blegen, 2017; Brooks et al., 2018).

Supplementary Information The online version contains supplementary material available at https://doi. org/10.1007/s41982-021-00109-1.

Acknowledgements I thank the National Museum of Kenya for access to the collections. Christian Tryon kindly provided the unpublished data on the site of Nyogonyek. Chris Clarkson and James Blinkhorn contributed useful discussions on some of the ideas presented herein. I am extremely grateful to Christian Tryon, John Gowlett, Kathleen Kuman, and Manuel Will whose constructive comments on a draft of this manuscript significantly improved it.

Data Availability The data analysed is included as supplementary material. The original artefacts are housed in the National Museum of Kenya.

\section{Declarations}

Conflict of Interest The author declares no competing interests.

Open Access This article is licensed under a Creative Commons Attribution 4.0 International License, which permits use, sharing, adaptation, distribution and reproduction in any medium or format, as long as you give appropriate credit to the original author(s) and the source, provide a link to the Creative Commons licence, and indicate if changes were made. The images or other third party material in this article are included in the article's Creative Commons licence, unless indicated otherwise in a credit line to the material. If material is not included in the article's Creative Commons licence and your intended use is not permitted by statutory regulation or exceeds the permitted use, you will need to obtain permission 
directly from the copyright holder. To view a copy of this licence, visit http://creativecommons.org/licen ses/by/4.0/.

\section{References}

Arzarello, M., Boudad, L., Peretto, C., Guislain, S., \& Aarab, M. (2012). Le débitage Levallois du site d'Amane Oukider (Sud-Est du Maroc): Analyse technologique d'un assemblage standardisé. Comptes Rendus Palevol, 11(8), 567-574.

Barham, L., Tooth, S., Duller, G. A., Plater, A. J., \& Turner, S. (2015). Excavations at site C North, Kalambo Falls, Zambia: New insights into the Mode 2/3 transition in south-central Africa. Journal of African Archaeology, 13(2), 187-214.

Biberson, P. (1961). Le Paléolithique inférieur du Maroc atlantique (Vol. 1). Service des antiquités du Maroc.

Blegen, N. (2017). The earliest long-distance obsidian transport: Evidence from the 200 ka Middle Stone Age Sibilo School Road Site, Baringo, Kenya. Journal of Human Evolution, 103, 1-19.

Blegen, N., Jicha, B. R., \& McBrearty, S. (2018). A new tephrochronology for early diverse stone tool technologies and long-distance raw material transport in the Middle to Late Pleistocene Kapthurin Formation, East Africa. Journal of Human Evolution, 121, 75-103.

Blinkhorn, J., Groucutt, H. S., Scerri, E. M., Petraglia, M. D., \& Blockley, S. (2021). Directional changes in Levallois core technologies between Eastern Africa, Arabia, and the Levant during MIS 5. Scientific Reports, 11(1), 1-11.

Boëda, E. (1994). Le concept Levallois, variabilité des méthodes. CNRS éditions.

Brantingham, P. J., \& Kuhn, S. L. (2001). Constraints on Levallois core technology: A mathematical model. Journal of Archaeological Science, 28(7), 747-761.

Brooks, A. S., Yellen, J. E., Potts, R., Behrensmeyer, A. K., Deino, A. L., Leslie, D. E., et al. (2018). Long-distance stone transport and pigment use in the earliest Middle Stone Age. Science, 360(6384), 90-94.

Brugal, J., \& Denys, C. (1989). Vertebres du site acheuleen d'Isenya (Kenya, District de Kajiado). Implications paleoecologiques et paleobiogeographiques. Comptes Rendus De L'académie Des Sciences, Paris, 308, 1503-1508.

Bruner, E. (2021). Evolving human brains: Paleoneurology and the fate of Middle Pleistocene. Journal of Archaeological Method and Theory, 28(1), 76-94.

Chiotti, L., Dibble, H. L., Olszewski, D. I., McPherron, S. P., \& Schurmans, U. A. (2009). Middle Palaeolithic lithic technology from the western High Desert of Egypt. Journal of Field Archaeology, 34(3), 307-318.

Clark, J. D. (1954). The Prehistoric Cultures of the Horn of Africa. Cambridge University Press.

Clark, J. D., Cormack, J., \& Chin, S. (2001). Kalambo Falls Prehistoric Site: Volume 3, the Earlier Cultures: Middle and Earlier Stone Age (Vol. 3). Cambridge University Press.

Clarkson, C. (2013). Measuring core reduction using 3D flake scar density: A test case of changing core reduction at Klasies River Mouth, South Africa. Journal of Archaeological Science, 40, 4348-4357.

Cornelissen, E. (1992). Site GNJH-17 and Its Implications for the Archaeology of the Kapthurin Formation, Baringo, Kenya (Vol. 133, Annales Sciences Humaines). Musée Royal de l'Afrique Centrale.

de la Torre, I., \& Mora, R. (2018). Technological behaviour in the early Acheulean of EF-HR (Olduvai Gorge, Tanzania). Journal of Human Evolution, 120, 329-377.

de la Torre, I., Mora, R., Arroyo, A., \& Benito-Calvo, A. (2014). Acheulean technological behaviour in the middle Pleistocene landscape of Mieso (East-Central Ethiopia). Journal of Human Evolution, $76,1-25$.

Duller, G. A., Tooth, S., Barham, L., \& Tsukamoto, S. (2015). New investigations at Kalambo Falls, Zambia: Luminescence chronology, site formation, and archaeological significance. Journal of Human Evolution, 85, 111-125. 
Durkee, H., \& Brown, F. H. (2014). Correlation of volcanic ash layers between the Early Pleistocene Acheulean sites of Isinya, Kariandusi, and Olorgesailie, Kenya. Journal of Archaeological Science, 49, 510-517.

Gallotti, R., Muttoni, G., Lefèvre, D., Degeai, J.-P., Geraads, D., Zerboni, A., et al. (2021). First high resolution chronostratigraphy for the early North African Acheulean at Casablanca (Morocco). Scientific Reports, 11(1), 1-14.

Goren-Inbar, N., Lister, A., Werker, E., \& Chech, M. (1994). A butchered elephant skull and associated artifacts from the Acheulian site of Gesher Benot Ya'aqov, Israel. Paléorient, 20, 99-112.

Goren-Inbar, N., Alperson-Afil, N., Sharon, G., \& Herzlinger, G. (2018). The Acheulian site of Gesher Benot Ya'aqov Volume IV: The Lithic Assemblages. Springer.

Gowlett, J. (1984). Mental abilities of early man: A look at some hard evidence. In R. Foley (Ed.), Hominid Evolution and Community Ecology (pp. 167-192). Academic Press.

Gowlett, J. (1990). Technology, Skill, and the Psychosocial Sector in the Long Term of Human Evolution. Archaeological Review from Cambridge, 9(1), 82-103.

Gowlett, J. (1999). Lower and Middle Pleistocene archaeology of the Baringo Basin. In P. Andrews \& P. Banham (Eds.), Late Cenozoic environments and hominid evolution: A tribute to Bill Bishop (pp. 123-141). The Geological Society.

Gowlett, J. (2006). The elements of design form in Acheulean bifaces: Modes, modalities, rules, and language. In N. Goren-Inbar \& G. Sharon (Eds.), Axe Age: Acheulian Toolmaking from Quarry to Discard (pp. 203-221). Equinox.

Gowlett, J., \& Crompton, R. (1994). Kariandusi: Acheulean morphology and the question of allometry. African Archaeological Review, 12(1), 3-42.

Gowlett, J., Crompton, R., \& Yu, L. (2001). Allometric comparisons between Acheulean and Sangoan large cutting tools at Kalambo Falls. In J. D. Clark (Ed.), Kalambo Falls prehistoric site (Vol. 3, pp. 612-619). Cambridge University Press.

Hardaker, T., \& Dunn, S. (2005). The flip test-A new statistical measure for quantifying symmetry in stone tools. Antiquity, 79(306). http://www.antiquity.ac.uk/projgall/hardaker306/.

IBM,C. (2019). IBM SPSS Statistics for Windows (27.0). IBM Corp.

Isaac, G. L., \& Isaac, B. (1977). Olorgesailie: Archeological studies of a Middle Pleistocene lake basin in Kenya. University of Chicago Press.

Jagher, R. (2016). Nadaouiyeh Aïn Askar, an example of Upper Acheulean variability in the Levant. Quaternary International, 411, 44-58.

Jung, J., Cloutman, L. L., Binney, R. J., \& Ralph, M. A. L. (2017). The structural connectivity of higher order association cortices reflects human functional brain networks. Cortex, 97, 221-239.

Kuman, K. (2001). An Acheulean factory site with prepared core technology near Taung, South Africa. The South African Archaeological Bulletin, 56, 8-22.

Leader, G. M., Abdolahzadeh, A., Lin, S. C., \& Dibble, H. L. (2017). The effects of platform beveling on flake variation. Journal of Archaeological Science: Reports, 16, 213-223.

Leader, G. M., Kuman, K., Gibbon, R., \& Granger, D. (2018). Early Acheulean organised core knapping strategies ca. 1.3 Ma at Rietputs 15, Northern Cape Province, South Africa. Quaternary International, 480, 16-28.

Leakey, L. S. B. (1931). The Stone Age Cultures of Kenya Colony. Cambridge University Press.

Leakey, M., Tobias, P. V., Martyn, J. E., \& Leakey, R. E. (1969). An Acheulean industry with prepared core technique and the discovery of a contemporary hominid mandible at Lake Baringo, Kenya. Proceedings of the Prehistoric Society, 35, 48-76.

Li, H., Kuman, K., Lotter, M. G., Leader, G. M., \& Gibbon, R. J. (2017). The Victoria West: earliest prepared core technology in the Acheulean at Canteen Kopje and implications for the cognitive evolution of early hominids. Royal Society Open Science, 4(6), 170288.

Lin, S. C., Rezek, Z., Braun, D., \& Dibble, H. L. (2013). On the utility and economization of unretouched flakes: The effects of exterior platform angle and platform depth. American Antiquity, 78(4), 724-745.

Lombard, M., \& Haidle, M. N. (2012). Thinking a bow-and-arrow set: Cognitive implications of Middle Stone Age bow and stone-tipped arrow technology. Cambridge Archaeological Journal, 22(2), 237.

McBrearty, S. (1999). Archaeology of the Kapthurin Formation. In P. Andrews \& P. Banham (Eds.), Late Cenozoic environments and hominid evolution: A tribute to Bill Bishop (pp. 143-156). The Geological Society. 
McBrearty, S. (2001). The Middle Pleistocene of East Africa. In L. Barham \& K. Robson-Brown (Eds.), Human Roots: Africa and Asia in the Middle Pleistocene (pp. 81-97). Western Academic and Specialist Press.

Moncel, M.-H., Ashton, N., Arzarello, M., Fontana, F., Lamotte, A., Scott, B., et al. (2020). Early Levallois core technology between marine isotope stage 12 and 9 in Western Europe. Journal of human Evolution, 139, 102735.

Muller, A., Clarkson, C., \& Shipton, C. (2017). Measuring behavioural and cognitive complexity in lithic technology throughout human evolution. Journal of Anthropological Archaeology, 48, 166-180.

Newcomer, M. H. (1971). Some quantitative experiments in handaxe manufacture. World Archaeology, 3(1), 85-94.

Njau, J. K., Herrmann, E. W., Ruck, L., Pante, M., Farrugia, P., Toth, N., et al. (2020). Core stratigraphy constrains Bed IV archaeological record at HEB site, Olduvai Gorge, Tanzania. Palaeogeography, Palaeoclimatology, Palaeoecology, 552, 109773.

Noll, M. P. (2000). Components of Acheulean lithic assemblage variability at Olorgesailie. University of Illinois at Urbana-Champaign.

Owen, R. B., Potts, R., Behrensmeyer, A. K., \& Ditchfield, P. (2008). Diatomaceous sediments and environmental change in the Pleistocene Olorgesailie Formation, southern Kenya Rift Valley. Palaeogeography, Palaeoclimatology, Palaeoecology, 269(1), 17-37.

Pleurdeau, D., Hovers, E., Assefa, Z., Asrat, A., Pearson, O., Bahain, J.-J., et al. (2014). Cultural change or continuity in the late MSA/Early LSA of southeastern Ethiopia? The site of Goda Buticha, Dire Dawa area. Quaternary International, 343, 117-135.

Raynal, J.-P., Alaoui, F. S., Geraads, D., Magoga, L., \& Mohi, A. (2001). The earliest occupation of North-Africa: The Moroccan perspective. Quaternary International, 75(1), 65-75.

Richter, D., Grün, R., Joannes-Boyau, R., Steele, T. E., Amani, F., Rué, M., et al. (2017). The age of the hominin fossils from Jebel Irhoud, Morocco, and the origins of the Middle Stone Age. Nature, 546(7657), 293-296.

Roche, H., Brugal, J.-P., Lefevre, D., Ploux, S., \& Texier, P.-J. (1988). Isenya: état des recherches sur un nouveau site acheuléen d'Afrique orientale. African Archaeological Review, 6(1), 27-55.

Roe, D. A. (1994). A metrical analysis of selected sets of handaxes and cleavers from Olduvai Gorge. In M. Leakey (Ed.), Olduvai Gorge (Vol. 5, pp. 1968-1971). Cambridge University Press.

Roe, D. A. (2001). The Kalambo Falls large cutting tools: a comparative metrical and statistical analysis. In J. D. Clark (Ed.), Kalambo Falls prehistoric site (Vol. 3, pp. 492-599). Cambridge University Press.

Rots, V., Van Peer, P., \& Vermeersch, P. M. (2011). Aspects of tool production, use, and hafting in Palaeolithic assemblages from Northeast Africa. Journal of Human Evolution, 60(5), 637-664.

Ryan, W. B., Carbotte, S. M., Coplan, J. O., O’Hara, S., Melkonian, A., Arko, R., et al. (2009). Global multi-resolution topography synthesis. Geochemistry, Geophysics, Geosystems, 10(3), Q03014

Sahle, Y., Hutchings, W. K., Braun, D. R., Sealy, J. C., Morgan, L. E., Negash, A., et al. (2013). Earliest stone-tipped projectiles from the Ethiopian Rift date to $>279,000$ years ago. PLoS One, 8(11), e78092.

Sahle, Y., Beyene, Y., Defleur, A., Asfaw, B., WoldeGabriel, G., Hart, W. K., et al. (2019). Revisiting Herto: New evidence of Homo sapiens from Ethiopia. In Y. Sahle, H. Reyes-Centeno, \& C. Bentz (Eds.), Modern human origins and dispersal (pp. 73-104). Kerns Verlag.

Sano, K., Beyene, Y., Katoh, S., Koyabu, D., Endo, H., Sasaki, T., et al. (2020). A 1.4-million-year-old bone handaxe from Konso, Ethiopia, shows advanced tool technology in the early Acheulean. Proceedings of the National Academy of Sciences, 117(31), 18393-18400.

Sharon, G. (2009). Acheulian Giant-Core Technology. Current Anthropology, 50(3), 335-367.

Sharon, G., \& Beaumont, P. (2006). Victoria West: A highly standardized prepared core technology. In N. Goren-Inbar \& G. Sharon (Eds.), Axe age: Acheulian toolmaking from Quarry to Discard (pp. 181-200). Equinox.

Sharon, G. (2007). Acheulian Large Flake Industries: Technology, Chronology, and Significance (BAR International Series). Archaeopress.

Shimelmitz, R., \& Kuhn, S. L. (2018). The toolkit in the core: There is more to Levallois production than predetermination. Quaternary International, 464, 81-91.

Shipton, C. (2011). Taphonomy and Behaviour at the Acheulean Site of Kariandusi, Kenya. African Archaeological Review, 28(2), 141-155.

Shipton, C. (2013). A Million Years of Hominin Sociality and Cognition: Acheulean Bifaces in the Hunsgi-Baichbal Valley. Archaeopress. 
Shipton, C. (2016). Hierarchical Organization in the Acheulean to Middle Palaeolithic Transition at Bhimbetka, India. Cambridge Archaeological Journal, 26(4), 601-618.

Shipton, C. (2018). Biface knapping skill in the East African Acheulean: Progressive trands and random walks. African Archaeological Review, 35, 107-131.

Shipton, C. (2019). The evolution of social transmission in the Acheulean. In K. Overmann \& F. L. Coolidge (Eds.), Squeezing Minds from Stones (pp. 332-354). Oxford University Press.

Shipton, C. (2020). The unity of Acheulean culture. In H. Groucutt (Ed.), Culture History and Convergent Evolution: Can we detect populations in prehistory? (pp. 13-27). Springer.

Shipton, C., \& Clarkson, C. (2015). Flake scar density and handaxe reduction intensity. Journal of Archaeological Science: Reports, 2, 169-175.

Shipton, C., Clarkson, C., Pal, J. N., Jones, S. C., Roberts, R. G., Harris, C., et al. (2013). Generativity, hierarchical action and recursion in the technology of the Acheulean to Middle Palaeolithic transition: A perspective from Patpara, the Son Valley, India. Journal of Human Evolution, 65, 93-108.

Shipton, C., Blinkhorn, J., Breeze, P. S., Cuthbertson, P., Drake, N., Groucutt, H. S., et al. (2018). Acheulean technology and landscape use at Dawadmi, central Arabia. PLoS One, 13(7), e0200497.

Shipton, C., Clarkson, C., \& Cobden, R. (2018b). Were Acheulean bifaces deliberately made symmetrical? Archaeological and experimental evidence. Cambridge Archaeological Journal, 29, 65-79.

Shipton, C., Blinkhorn, J., Archer, W., Kourampas, N., Roberts, P., Prendergast, M., et al. (2021). The Middle to Later Stone Age transition at Panga ya Saidi in the tropical coastal forest of eastern Africa. Journal of human Evolution, 153, 102954.

Stout, D., Apel, J., Commander, J., \& Roberts, M. (2014). Late Acheulean technology and cognition at Boxgrove, UK. Journal of Archaeological Science, 41, 576-590.

Tallon, P. (1978). Geological setting of the hominid fossils and Acheulian artifacts from the Kapthurin Formation, Baringo District, Kenya. In W. Bishop (Ed.), Geological Background to Fossil Man. Scottish Academic Press.

Toth, N. (2001). Experiments in quarrying large flake blanks at Kalambo Falls. In J. D. Clark (Ed.), Kalambo Falls prehistoric site (Vol. 3, pp. 600-604). Cambridge University Press.

Tryon, C. A. (2006). "Early" Middle Stone Age Lithic Technology of the Kapthurin Formation (Kenya). Current Anthropology, 47(2), 367-375.

Tryon, C. A., \& McBrearty, S. (2006). Tephrostratigraphy of the Bedded Tuff Member (Kapthurin Formation, Kenya) and the nature of archaeological change in the later Middle Pleistocene. Quaternary Research, 65(3), 492-507.

Tryon, C. A., McBrearty, S., \& Texier, P.-J. (2005). Levallois lithic technology from the Kapthurin Formation, Kenya: Acheulian origin and Middle Stone Age diversity. African Archaeological Review, 22(4), 199-229.

Tryon, C. A., Roach, N. T., \& Logan, M. A. V. (2008). The Middle Stone Age of the northern Kenyan Rift: Age and context of new archaeological sites from the Kapedo Tuffs. Journal of Human Evolution, 55(4), 652-664.

Tryon, C. A. (2002). Middle pleistocene sites from the southern Kapwurin Formation of Kenya. Nyame Akuma, 57, 6-13.

Van Peer, P. (1992). The Levallois Reduction Strategy (Vol. 13). Prehistory Press.

Wragg Sykes, R. (2015). To see a world in a hafted tool: Birch pitch composite technology, cognition and memory in Neanderthals. In F. Coward, R. Hosfield, M. Pope, \& F. Wenban-Smith (Eds.), Settlement, Society and Cognition in Human Evolution: Landscapes in Mind (pp. 117-137). Cambridge University Press.

Publisher's Note Springer Nature remains neutral with regard to jurisdictional claims in published maps and institutional affiliations. 